DIW BERLIN

Discussion Papers

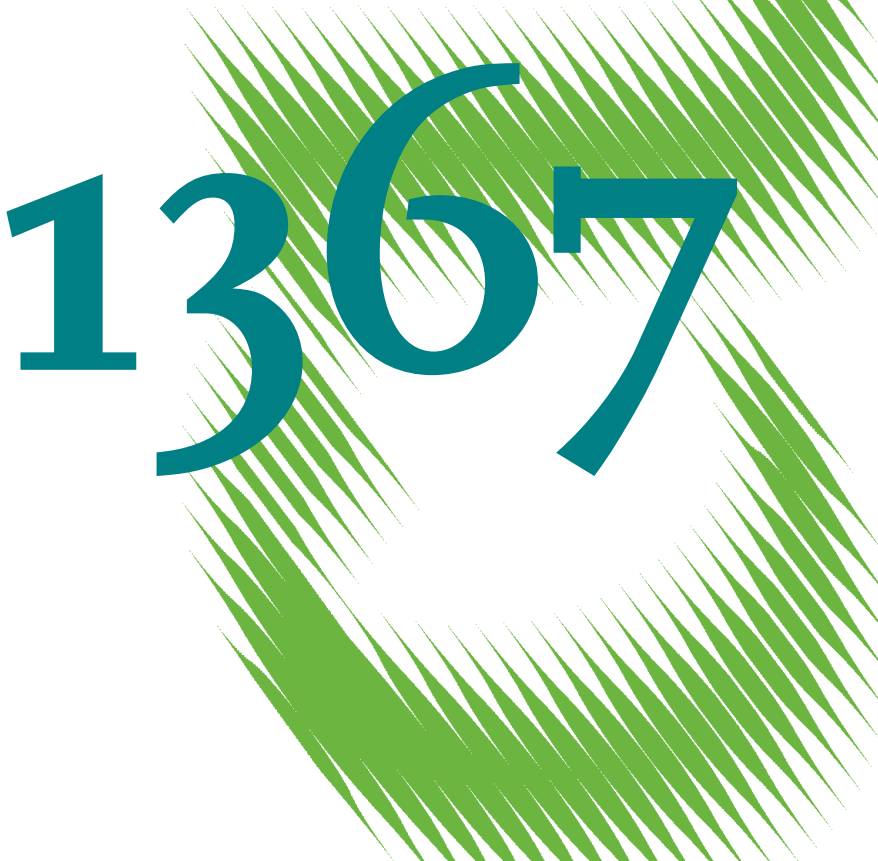

Search-Based Endogenous

Illiquidity and the Macroeconomy 
Opinions expressed in this paper are those of the author(s) and do not necessarily reflect views of the institute.

IMPRESSUM

(C) DIW Berlin, 2014

DIW Berlin

German Institute for Economic Research

Mohrenstr. 58

10117 Berlin

Tel. $+49(30) 89789-0$

Fax +49 (30) $89789-200$

http://www.diw.de

ISSN print edition $1433-0210$

ISSN electronic edition 1619-4535

Papers can be downloaded free of charge from the DIW Berlin website:

http://www.diw.de/discussionpapers

Discussion Papers of DIW Berlin are indexed in RePEc and SSRN:

http://ideas.repec.org/s/diw/diwwpp.html

http://www.ssrn.com/link/DIW-Berlin-German-Inst-Econ-Res.html 


\title{
Search-Based Endogenous Illiquidity and the Macroeconomy*
}

\author{
Wei Cui ${ }^{\ddagger}$ Sören Radde ${ }^{\S}$
}

March, 2014

\begin{abstract}
We endogenize asset liquidity in a dynamic general equilibrium model with search frictions on asset markets. In the model, asset liquidity is tantamount to the ease of issuance and resaleability of private financial claims, which is driven by investors' participation on the search market. Limited resaleability of private claims creates a role for liquid assets, such as government bonds or fiat money, to ease funding constraints. We show that liquidity and asset prices positively co-move. When the capacity of the asset market to channel funds to entrepreneurs deteriorates, the hedging value of liquid assets increases. Our model is thus able to match the flight to liquidity observed during recessions. Finally, we show that investors' search market participation is more intense in a constrained efficient economy.
\end{abstract}

Keywords: endogenous asset liquidity; search frictions

classification: E22; E44; E58.

${ }^{*}$ The views expressed in this paper are those of the authors and do not necessarily reflect those of the European Central Bank (ECB). We gratefully acknowledge insightful discussions with Frank Heinemann and Nobuhiro Kiyotaki. We also greatly benefited from discussions with Marco Bassetto, Tobias Broer, Mariacristina De Nardi, Thomas Sargent, Robert Shimer, Ted Temzelides, and Morten Ravn. Finally, we thank seminar participants at Princeton, Humboldt University, DIW Berlin, the 2013 SED Annual Meeting in Seoul, the 2013 7th Nordic Macro Symposium, and the 2013 Vienna Macro Workshop for their comments and DIW Berlin for providing financial support for this project.

${ }^{\ddagger}$ Department of Economics, University College London. Email: w.cui@ucl.ac.uk

$\S$ European Central Bank, German Institute for Economic Research (DIW Berlin) and Technische Universität Berlin. Email: soeren.radde@ecb.europa.eu 



\section{Introduction}

Illiquidity of privately issued financial assets arises from impediments to their transactions. Empirical evidence points to procyclical variation in the market liquidity of a wide range of financial assets. ${ }^{1}$ The view that asset liquidity dries up during recessions has been further reinforced by the 2007-2009 financial crisis, when illiquidity problems were most pronounced for commercial paper and asset-backed securities. ${ }^{2}$

Asset illiquidity tends to reduce firms' ability to issue debt or equity. ${ }^{3}$ This effect creates a role for liquid assets, such as fiat money or government bonds, which provide insurance against funding constraints as they can be readily used for financing purposes at any time. When funding constraints tighten in recessions, firms tend to rebalance their portfolios towards such liquid assets - a phenomenon referred to as "flight to liquidity".

The idea of liquidity hoarding as a hedging device against funding constraints goes back to Keynes (1936) and Tobin (1969). The effect of variations in asset liquidity on portfolio choices and aggregate fluctuations is, however, often ignored in state-of-the-art dynamic general equilibrium models. A notable exception is Kiyotaki and Moore (2012) (henceforth, KM), who demonstrate how asset market liquidity interact with aggregate fluctuations.

The key idea of KM is that firms can only sell an exogenously determined fraction of private claims to finance new investment. In contrast, money or government bonds can be fully sold and thus provide a liquidity service. When the resaleable fraction of private claims falls, financing constraints tighten and agents shift to money. As a result, real investment and production fall and a recession begins. However, as pointed out by Shi (2012), treating liquidity variations as exogenous leads to counterfactual asset price dynamics: A negative shock to asset resaleability reduces the supply of financial assets, while demand remains relatively stable since the quality of investment projects is unaffected by liquidity shocks. The negative supply shock induces an asset price boom that is at odds with the data.

To tackle this problem, we propose a framework in which endogenous variation in asset liquidity interacts with macroeconomic conditions. To this end, we incorporate a search

\footnotetext{
${ }^{1}$ Studies by Huberman and Halka (2001), Chordia, Roll, and Subrahmanyam (2001), and Chordia, Sarkar, and Subrahmanyam (2005) assert that market liquidity is procyclical and highly correlated across asset classes such as bonds and stocks in the US. This observation implies that common factors drive liquidity.

${ }^{2}$ Dick-Nielsen, Feldhütter, and Lando (2012) identify a break in the market liquidity of corporate bonds at the onset of the sub-prime crisis. The liquidity component of spreads of all but AAA rated bonds increased and turnover rates declined, making refinancing on market more difficult. Commercial paper (CP), which is largely traded on a search market with dealers as match-makers, experienced large illiquidity in recessions reported by Anderson and Gascon (2009). In addition, money market mutual funds, the main investors in the CP market, shifted to highly liquid and secure government securities. Finally, Gorton and Metrick (2012) show that the repo market has registered strongly increasing haircuts during the crisis.

${ }^{3}$ In fact, U.S. nonfinancial firms only fund $35 \%$ of fixed investment through financial markets, of which $76 \%$ through debt and equity issuance and $24 \%$ through portfolio liquidations (Ajello, 2012).
} 
market for financial assets into a dynamic macroeconomic model to endogenously determine the fraction of private claims that can be sold to finance new investment. The search market structure in our model is a stand-in for over-the-counter asset markets or financial intermediation through a banking sector, both of which involve a costly matching process between capital providers and seekers. The model shows how a drop in investor participation in the search market simultaneously decreases asset liquidity and prices, and thus exacerbates the funding constraints of firms, which dampens real investment and production. Our central contributions are (i) to demonstrate both analytically and numerically that endogenizing liquidity is essential to generate co-movement between asset liquidity and asset prices; and (ii) to show that shocks to the cost of financial intermediation are an important source of flight to liquidity and business cycles.

Consider an economy where privately issued financial claims are backed by cash flow from physical capital used for production. There is a continuum of households whose members are temporarily separated during periods. Some become workers, others entrepreneurs. Only the latter have access to investment opportunities for capital good creation. All household members are endowed with a portfolio of liquid assets (money) ${ }^{4}$ and private claims, which we interpret as a catch-all for privately issued assets such as corporate bonds and equity.

To finance investment, entrepreneurs exploit all available modes of funding: They issue new financial claims to their investment projects and liquidate existing asset portfolio. Money is readily available for financing purposes and hence commands a liquidity premium. Private claims (both new and old) are only partially liquid, because they are traded on the search market. Asset liquidity is measured by the fraction of private claims that can be sold or resold on this market in a given period. Due to the limited funding from asset markets, entrepreneurs are financing-constrained and cannot fund the first-best level of investment.

Participation in the search market is costly for both buyers and sellers. Once individual buyers and sellers meet, the transaction price is determined in a bargaining process, as in the labor search literature advanced by Diamond (1982), Mortensen and Pissarides (1994), and Shimer (2005). This market structure intends to emulate the features of over-the-counter (OTC) markets, in which a large fraction of corporate bonds, asset-backed securities, and private equity is traded and in which costs arise from information acquisition as well as brokerage and settlement services. ${ }^{5}$ Alternatively, our framework can also be interpreted as a reduced-form approach towards modeling financial intermediation. In particular, the search market structure captures the costly matching process between savers (investors) and

\footnotetext{
${ }^{4}$ For simplicity, we consider all government-issued assets as money. Our framework could easily be extended to general interest bearing liquid assets as illustrated in the model section.

${ }^{5}$ See, for example, Dick-Nielsen, Feldhütter, and Lando (2012), Bao, Pan, and Wang (2011), Anderson and Gascon (2009).
} 
the corporate sector through financial intermediaries.

We consider two types of exogenous shocks: an aggregate productivity shock and a symmetric shock to the market participation costs of buyers and sellers, which we interpret as an "intermediation cost shock". We use data on government-issued assets and GDP to estimate the size and persistence of these shocks.

Negative aggregate productivity (TFP) shocks decrease the return to capital, make investment into capital goods less attractive, and, hence crowd out investors from the search market. Negative intermediation cost shocks, on the other hand, make investment into liquid assets more attractive. This reduces the incentive for investors to post costly buy orders on the search market. In either case, the fall in demand on the asset market exceeds that of supply, such that sellers have a lower chance of encountering a buyer. Hence, the sales rate or liquidity - of financial claims drops. Because a lower sales rate implies that entrepreneurs need to retain a larger equity stake in new investment projects, their financing constraints tighten and the option of breaking off negotiations becomes less valuable. Entrepreneurs are thus willing to accept a lower transaction price. In the aggregate, lower asset liquidity and prices restrict the funding available to entrepreneurs and, thereby, reduce real investment.

While both shocks generate procyclical asset liquidity and prices, only intermediation cost shocks induce a pronounced flight to liquidity. In the case of persistent adverse TFP shocks, investors have a weaker incentive to hedge against future illiquidity of private claims, because of lower current and future returns to capital. Adverse intermediation cost shocks, however, do not deteriorate the quality of investment either today or tomorrow. Therefore, investors value the hedging service provided by liquid assets more strongly.

To our knowledge, we are the first to incorporate endogenous asset liquidity in a dynamic macroeconomic model in a tractable way and to explore the feedback effects between liquidity and the real economy. ${ }^{6}$ We further discuss whether the decentralized search market is characterized by the constrained efficient degree of search intensity. This exercise is similar to Acemoglu and Shimer (1999) in setting up the constrained planner's problem with search frictions and risk averse agents. However, the endogenous portfolio choice and asset prices complicate the planner's problem. We show how to substitute out asset prices and portfolio choices in the planner's problem to obtain an "implementability condition" borrowed from the optimal taxation literature, such as Lucas and Stokey (1983).

Under our calibration, the social planner chooses a higher degree of investor participation in the search market compared to the decentralized economy, which implies higher steady state asset liquidity. Intuitively, the social planner internalizes the benefit of relaxing entrepreneurs' financing constraints by increasing asset resaleability. In addition, we derive a

\footnotetext{
${ }^{6}$ A recent study by Yang (2013) also considers endogenous asset liquidity. Our framework goes beyond this paper in that we model liquid and illiquid assets and the corresponding portfolio choice simultaneously.
} 
modified "Hosios" condition, which shows that the efficiency of the decentralized economy depends on the institutional design of the search market, i.e. the bargaining power of the sellers or the supply elasticity of matches.

Relationship to the Literature. We follow KM in that we model liquidity differences between private claims and government-issued assets. As highlighted by KM, the irrelevance result of Wallace (1981) on the neutrality of central banks' portfolios no longer holds. In fact, open market operations that change the composition of liquid and illiquid assets in agents' portfolios have real effects. Del Negro, Eggertsson, Ferrero, and Kiyotaki (2011) analyze such "unconventional policy" after an exogenous fall in liquidity in an extended version of KM's model. With standard monetary policy constrained by the "Zero Lower Bound", liquidity injections effectively dampen the liquidity shortfall and stabilize the economy. ${ }^{7}$

As argued by Shi (2012), negative exogenous liquidity shocks lead to counterfactual asset price boom, highlighting the need to model asset liquidity endogenously. The search literature provides a natural theory of endogenous liquidity as in Lagos and Rocheteau (2009) and has been applied to a wide range of markets such as housing ${ }^{8}$, OTC markets for assetbacked securities, corporate bonds, federal funds, private equity, etc. ${ }^{9}$ This line of research shows that search frictions can explain substantial variation in various measures of asset market liquidity, such as bid-ask spreads, trade volume, and trading delays.

Work by Haan, Ramey, and Watson (2003), Wasmer and Weil (2004), and PetroskyNadeau and Wasmer (2013) has emphasized the role of search and matching frictions in credit markets and their impact on the macroeconomy, ${ }^{10}$ but does not study asset prices and portfolio rebalancing. In contrast, we highlight that asset liquidity fluctuations have important implications for asset prices and individuals' portfolio compositions and hence on the real economy.

An alternative approach to endogenizing liquidity uses information frictions. Eisfeldt (2004) develops a partial equilibrium model with adverse selection in asset markets, in which investment and trading volume are amplified if asset liquidity endogenously varies with productivity. Dynamic adverse selection, asset prices, and trading delays are analyzed in an endowment economy framework by Guerrieri and Shimer (2012). While endogenizing asset liquidity, these studies do not consider the feedback effects of fluctuations in liquidity on production and employment. A notable exception is Kurlat (2013) who extends KM with

\footnotetext{
${ }^{7}$ More generally, Kara and Sin (2013) show that market liquidity frictions induce a trade-off between output and inflation stabilization off the ZLB that can be attenuated by quantitative easing measures.

${ }^{8}$ See e.g. Wheaton (1990) and Ungerer (2012).

${ }^{9}$ See e.g. Duffie, Gârleanu, and Pedersen (2005, 2007); Ashcraft and Duffie (2007); Feldhutter (2011).

${ }^{10}$ As shown in Beaubrun-Diant and Tripier (2013), search frictions also help explain salient business cycle features of bank lending relationships, such as countercyclical net interest margins and loan separation rates.
} 
endogenous resaleability through adverse selection. However, this paper does not consider the liquidity service provided by less information-sensitive assets in relaxing financing constraints. In Eisfeldt and Rampini (2009) firms need to accumulate liquid funds in order to finance investment opportunities. While the supply of liquid assets affects investment, secondary markets for asset sales are shut off as an alternative means of financing. In contrast to these contributions, we jointly model endogenous liquidity on primary and secondary asset markets, the role of liquid assets as the lubricant of investment financing, and asset liquidity's feedback effects on business cycles. ${ }^{11}$

Our framework also differs along important dimensions from search-theoretic models of money such as Lagos and Wright (2005) and Rocheteau and Wright (2005). In this literature, money has a transaction function in anonymous search markets. Recent extensions include privately created liquid assets such as claims to capital (Lagos and Rocheteau, 2008) or bank-deposits (Williamson, 2012) as media of exchange. Our framework rather emphasizes the role of financial assets - both public and private - as stores of value, i.e. money and equity claims are used for financing purposes. Moreover, our approach is able to generate endogenous variation in asset liquidity and the associated premia, because private claims are subject to search frictions themselves, rather than serving to overcome such frictions on other markets. These differences notwithstanding, a common tenet is that liquid assets play an important role in economic transactions by relaxing deep financial frictions.

By studying intermediation cost shocks which affect asset market liquidity, we also build on the literature on financial shocks. Recent contributions by Jermann and Quadrini (2012), Christiano, Motto, and Rostagno (2014), and Jaccard (2013) identify financial shocks as an important source of business cycle fluctuations. Our approach shows how such shocks may be endogenously amplified within financial markets.

Finally, we transfer the Ramsey "primal approach" to the study of optimal policy in the presence of financial frictions. Since Lucas and Stokey (1983), this approach has been intensively applied to optimal taxation ${ }^{12}$ and we view it as a valuable method for addressing optimal policy in response to financial frictions in general.

The rest of the paper is organized as follows: Section 2 presents the model. Section 3 contains our main analytical results, characterizes the bargaining solution on the asset search market and the competitive equilibrium and outlines the constrained social planner's problem. In Section 4, we discuss our calibration strategy and numerical examples for the dynamic behavior of our economy. Section 5 concludes.

\footnotetext{
${ }^{11}$ Asset illiquidity may further interact with financing constraints to induce delays in asset sales as in Cui (2013). This interaction prolongs shocks to the financing conditions of the private sectors and results in countercyclical productivity dispersion.

${ }^{12}$ See a survey by Chari and Kehoe (1999) and more recently Bhandari, Evans, Golosov, and Sargent (2013).
} 


\section{The Model Environment}

This model is a variant of a standard real business cycle (RBC) model. The key difference is that privately issued financial assets are not fully liquid because they are traded on a search market. In contrast, government-issued assets, such as fiat money or government bonds, are fully liquid and can thus be used for spot transactions. Throughout the model, we focus on an equilibrium in which this intrinsically worthless asset is valued for its liquidity service and hence accepted by all market participants.

Time is discrete and infinite $(t=0,1,2, \ldots)$. The economy has two sectors: households and final goods producers. There is a continuum of representative households and each has a unit measure of members. The members of each representative household are either entrepreneurs or workers. There are search frictions afflicting the purchase and sale of financial assets issued by previous and current entrepreneurs. In addition, liquid governmentissued assets can be traded on a spot market. ${ }^{13}$ Final goods producers generate output by renting capital and hiring labor from households. ${ }^{14}$

\subsection{Households}

Household Structure and Timing. At the beginning of $t$, aggregate exogenous states are realized, i.e., the aggregate productivity and the unit cost of trading private claims (introduced below). A representative household specifies policy rules for each member, i.e., the asset positions to be filled and the assets to be sold, consumption schedules, and labor supply.

Household members receive equal shares of assets accumulated from previous periods. Then, they receive a shock that determines their type, which is idiosyncratic across members and through time. With probability $\chi$ a member becomes an entrepreneur (type $u$ ) and with probability $(1-\chi)$ a worker (type $v) .{ }^{15}$ By the law of large numbers, each household thus consists of a fraction $\chi$ of entrepreneurs and a fraction $(1-\chi)$ of workers. Both groups are temporarily separated during each period and there is no consumption insurance between them. Workers earn wages by supplying labor. Entrepreneurs do not work, but only they have investment opportunities.

In the middle of $t$, final goods producers rent capital and labor from households to produce

\footnotetext{
${ }^{13}$ For simplicity, we do not model the government explicitly. Alternatively, one could have the government supplying a constant amount of fully liquid fiat money.

${ }^{14}$ They rebate profits back to households in the form of dividends. In equilibrium, profits and thus dividends are zero.

${ }^{15}$ Following the notation in the labor search literature, we denote workers as type $v$ and entrepreneurs as type $u$ members. The underlying logic is that workers post purchase orders on the search market which are akin to "vacant" asset positions, while entrepreneurs post assets for sale which are in a sense "unemployed" when lying idle on their balance sheets.
} 
consumption goods and the payoffs from private claims are thus realized. At the same time, household members trade liquid assets on a competitive market in exchange for consumption goods. Then, each household member meets a counterparty for trading each unit of private claims and bargains over the price (in terms of consumption goods). Entrepreneurs then invest in physical capital, after which workers and entrepreneurs consume.

At the end of $t$, members come together again to share their accumulated assets. All members hence enter the next period with an equal share of their household's assets. ${ }^{16}$

Preferences. The household objective is to maximize

$$
\mathbb{E}_{t} \sum_{s=0}^{\infty} \beta^{t+s}\left[U\left(c_{u, t+s}, c_{v, t+s}\right)-(1-\chi) h\left(n_{t+s}\right)\right]
$$

where $U\left(c_{u, t}, c_{v, t}\right)=\chi u\left(c_{u, t}\right)+(1-\chi) u\left(c_{v, t}\right)$ is the total utility derived from consumption by entrepreneurs $\left(c_{u, t}\right)$ and workers $\left(c_{v, t}\right)$, with $u\left(c_{j, t}\right)=\frac{c_{j, t}^{1-\sigma}-1}{1-\sigma}, j \in\{u, v\}$ (a standard CRRA utility function). $h\left(n_{t}\right)=\mu n_{t}$ captures the dis-utility derived from labor supply $n_{t}$. $\mathbb{E}_{t}$ is the expectation operator conditional on information at time $t$.

Balance Sheet. Physical capital $\left(K_{t}\right)$ is owned by households and rented to final goods producers such that capital earns a return. There is a claim to the future return of every unit of capital, which household members can either retain or offer for sale to outside investors. These claims can be sold at unit price $q_{t}$, which will be determined in the search market. In addition, households invest in risk-less (nominal) liquid assets $B_{t}$, with nominal price level $P_{t}$. Hence, at the onset of period $t$, households own a portfolio of liquid assets, equity claims on other households' return on capital, and own physical capital. These assets are financed by net worth plus equity claims issued against their own physical capital.

Claims to cash-flows generated by capital goods are sold on a search market. On this market, only a fraction of offered assets is matched to appropriate buyers, such that some claims remain unmatched. Selling claims to cash-flow from capital is akin to mortgaging the underlying capital stock. We assume that the fraction of previously unmortgaged physical capital $\left(K_{t}-S_{t}^{I}\right)$ that can be mortgaged is identical to the fraction of existing claims that can be sold on the search market. This simplification ensures that both existing equity and unmortgaged physical capital stock not only yield the same return, but are equally liquid. They will thus yield the same price on the search market and can be treated as perfect substitutes. In sum, we only need to keep track of net equity, defined as

$$
S_{t}=\underbrace{S_{t}^{O}}_{\text {equity claims on others' capital }}+\underbrace{K_{t}-S_{t}^{I}}_{\text {unmortgaged capital }} .
$$

\footnotetext{
${ }^{16}$ The representative household with temporarily separated agents has been introduced in Lucas (1990) and applied to the KM framework in Shi (2012) and Del Negro, Eggertsson, Ferrero, and Kiyotaki (2011).
} 
The financing structure gives rise to the beginning-of-period balance sheet in Table 1 .

Table 1: Household's Balance Sheet

\begin{tabular}{ll|ll}
\hline liquid assets & $B_{t} / P_{t}$ & equity issued & $q_{t} S_{t}^{I}$ \\
other's equity & $q_{t} S_{t}^{O}$ & & \\
capital stock & $q_{t} K_{t}$ & net worth & $q_{t} S_{t}+B_{t} / P_{t}$ \\
\hline
\end{tabular}

\subsubsection{The Representative Household's Problem}

Individual flow-of-funds. At the beginning of period $t$, let $s_{j t}$ and $b_{j t}$ be net equity and liquid assets for a typical household member $j$. The net equity evolves according to

$$
s_{j, t+1}=(1-\delta) s_{j, t}+i_{j, t}-m_{j, t},
$$

where $i_{j, t}$ is investment into capital goods, which creates an equal number of claims, and $m_{j, t}$ corresponds to asset sales. Let $c_{j, t}$ and $n_{j, t}$ denote consumption and labor supply, respectively. Finally, let $w_{t}$ be the wage and and $r_{t}$ the rental rate of capital.

In equilibrium, the household delegates equity purchases on the search market to workers, because they do not have investment opportunities $\left(i_{v, t}=0\right)$. Therefore, workers $j=v$ post asset positions $v_{t}$ to acquire new or old equity at unit cost $\kappa_{v}$. On the search market, each posted position is filled with probability $\phi_{v, t} \in[0,1]$. Accordingly, an individual buyer expects to purchase an amount

$$
m_{v, t}=-\phi_{v, t} v_{t} .
$$

Substituting out expected purchases on the search market, $m_{v, t}$, the evolution of workers' equity positions becomes

$$
s_{v, t+1}=(1-\delta) s_{v, t}+\phi_{v, t} v_{t},
$$

A worker's flow-of-funds constraint reads

$$
c_{v, t}+\kappa_{v} v_{t}+\frac{b_{v, t+1}}{P_{t}}=w_{t} n_{v, t}+r_{t} s_{v, t}-q_{t} \phi_{v, t} v_{t}+\frac{b_{v, t}}{P_{t}},
$$

where labor income and the return on equity and liquid assets are used to finance consumption, search costs, and the accumulation of equity claims and liquid assets. To simplify, we define the effective purchasing price of a unit of equity as

$$
q_{v, t} \equiv q_{t}+\frac{\kappa_{v}}{\phi_{v, t}}
$$


where $q$ captures the price and $\frac{\kappa_{v}}{\phi_{v}}$ represents search costs per transaction, which are scaled up by the probability of encountering a seller. By using (3), the flow-of-funds constraint (4) can be rewritten as

$$
c_{v, t}+q_{v, t} s_{v, t+1}+\frac{b_{v, t+1}}{P_{t}}=w_{t} n_{v, t}+r_{t} s_{v, t}+(1-\delta) q_{v, t} s_{v, t}+\frac{b_{v, t}}{P_{t}}
$$

Rather than purchasing equity claims on the search market, entrepreneurs $j=u$ decide how many assets $u_{t}$ to put up for sale at unit cost $\kappa_{u}$ in order to finance new investment $\left(i_{u, t}>0\right)$. These assets include existing equity claims on other households' capital stock and their own unmortgaged capital stock (in total $s_{u, t}$ ), plus claims on new investment, $i_{u, t}$. The amount of private financial claims that are up for sale is thus bounded from above by the existing stock of equity and the volume of new investment, $u_{t} \leq(1-\delta) s_{u, t}+i_{u, t}$. Offers are matched with a buyer with probability $\phi_{u, t} \in[0,1]$. Therefore, an individual entrepreneur expects to sell

$$
m_{u, t}=\phi_{u, t} u_{t}
$$

Again, we substitute out sales $m_{u, t}$, to retrieve the evolution of equity as

$$
s_{u, t+1}=(1-\delta) s_{u, t}+i_{u, t}-\phi_{u, t} u_{t}
$$

We now turn to an entrepreneur's flow-of-funds constraint

$$
c_{u, t}+i_{u, t}+\kappa_{u} u_{t}+\frac{b_{u, t+1}}{P_{t}}=r_{t} s_{u, t}+q_{t} \phi_{u, t} u_{t}+\frac{b_{u, t}}{P_{t}},
$$

where the returns on equity and liquid assets are used to finance consumption, search costs, and the accumulation of equity (with new investment taken into account) and liquid assets. If we define effective selling price of unit financial asset as

$$
q_{u, t} \equiv q_{t}-\frac{\kappa_{u}}{\phi_{u, t}}
$$

the flow-of-funds constraint (8) becomes

$$
c_{u, t}+i_{u, t}+q_{u, t}\left[s_{u, t+1}-i_{u, t}-(1-\delta) s_{u, t}\right]+\frac{b_{u, t+1}}{P_{t}}=r_{t} s_{u, t}+\frac{b_{u, t}}{P_{t}} .
$$

We focus on an economy in which privately issued assets are only partially liquid and the market price of capital exceeds the internal cost of creating new capital claims, i.e. $q_{t}>1 .^{17}$

\footnotetext{
${ }^{17}$ As shown in Corollary 1 , in a frictionless economy with costless search market participation the capital price approaches $q_{t}=1$. In this case, the internal equals the external cost of creating capital goods, such
} 
In this case, entrepreneurs will put as many assets as possible on sale to take full advantage of their investment opportunities, i.e. $u_{t}=(1-\delta) s_{u, t}+i_{u, t}$. This fact allows us to simplify the flow-of-funds constraint (10) by substituting out investment from (7) to obtain

$$
\begin{gathered}
c_{u, t}+q_{r, t} s_{u, t+1}=r_{t} s_{u, t}+\left[\phi_{u, t} q_{u, t}+\left(1-\phi_{u, t}\right) q_{r, t}\right](1-\delta) s_{u, t}+R_{t} \frac{b_{u, t}}{P_{t}}, \\
\text { where } \quad q_{r, t} \equiv \frac{1-\phi_{u, t} q_{u, t}}{1-\phi_{u, t}} .
\end{gathered}
$$

Importantly, $q_{r, t}$ is the effective replacement cost of existing assets. To see this, consider that due to the law of large numbers the ex ante probability of encountering buyers for a given asset portfolio equals the ex post fraction of assets that are effectively traded. Therefore, entrepreneurs can sell a fraction $\phi_{u, t}$ of their financial assets at price $q_{u, t}$. For every unit of new investment, they will accordingly need to make a down-payment $\left(1-\phi_{u, t} q_{u, t}\right)$ and retain a fraction $\left(1-\phi_{u, t}\right)$ as inside equity. With this interpretation, $q_{r, t}$ is indeed the effective replacement cost. ${ }^{18}$

Remark. The asset price $q_{t}$ and matching probabilities $\phi_{v, t}$ and $\phi_{u, t}$ are taken as given by households. These objects will be determined endogenously on the search market. To further simplify our analysis by abstracting from government policies, we treat government bonds as fiat money - formally,

$$
R_{t}=1
$$

Generalizing the set-up to interest-bearing government bonds would not change the main mechanism, which operates through the portfolio choice between liquid and illiquid assets. ${ }^{19}$

Aggregation. Recall that $j \in\{u, v\}$ indicates workers and entrepreneurs, respectively. We define aggregate type-specific variables as $X_{u, t} \equiv \chi x_{u, t}$ and $X_{v, t} \equiv(1-\chi) x_{v, t}$ and household-wide variables as the aggregation of workers' and entrepreneurs' quantities, i.e. $X_{t}=X_{v, t}+X_{u, t}$. For example, aggregate consumption is the sum of aggregate consumption of workers and entrepreneurs, i.e., $C_{t}=C_{v, t}+C_{u, t}$.

that capital production yields zero profits and financial constraints cease to exist. Empirically, the capital price captures Tobin's $q$, which ranges between 1.1 and 1.21 in the U.S. economy, i.e. well above 1. For this empirically relevant case, capital production is profitable, which reflects financial constraints of firms. During recessions $q_{t}$ typically falls and erodes firms' net worth, which tightens financing constraints further. This is because firms are leveraged, such that the contraction in their funding base due to the negative shock to net worth is strongly amplified.

${ }^{18}$ This down-payment price captures the effect of search costs on equity accumulation: higher search costs decrease the effective sales price, which increases the down-payment that in turn depresses equity accumulation. Therefore, the entrepreneurs' ability to leverage will be lower if search costs are higher.

${ }^{19}$ The detailed derivation of the model with interest-bearing government bonds and taxation is available upon request. 
For simplicity, we switch to recursive notation, i.e., let $x$ and $x^{\prime}$ denote $x_{t}$ and $x_{t+1}$. Note that all household members share their assets at the end of each period, such that entrepreneurs and workers are endowed with asset positions proportional to their mass at the beginning of the next period, i.e. $S_{u}=\chi S, S_{v}=(1-\chi) S, B_{u}=\chi B, B_{v}=(1-\chi) B$. Since entrepreneurs do not work, we also have that $N=N_{v}$. Given these simplifications, individual budget constraints (11) and (6) aggregate to

$$
\begin{gathered}
C_{u}+q_{r} S_{u}^{\prime}+\frac{B_{u}^{\prime}}{P}=\left[r+\left[\phi_{u} q_{u}+\left(1-\phi_{u}\right) q_{r}\right](1-\delta)\right] \chi S+\chi \frac{B}{P} \\
C_{v}+q_{v} S_{v}^{\prime}+\frac{B_{v}^{\prime}}{P}=w N+\left[r+q_{v}(1-\delta)\right](1-\chi) S+(1-\chi) \frac{B}{P} .
\end{gathered}
$$

The left-hand side (LHS) of equation (13) captures entrepreneurs' spending on consumptions and future equity (evaluated at the replacement costs), while the right-hand side (RHS) represents entrepreneurial net-worth, which derives from rental income from capital claims, the value of existing claims (of which a fraction $\phi_{u}$ is saleable and, hence, valued at $q_{u}$, while a fraction $\left(1-\phi_{u}\right)$ is retained and valued at the effective replacement costs $q_{r}$ ), and the return on money. Notice that households delegate purchases of equity claims (risky assets) and liquid assets (precautionary savings) entirely to workers. ${ }^{20}$ Accordingly, workers value equity claims at the purchase price $q_{v}$ as seen from the LHS of budget constraint (14). The RHS captures workers' resources, which are composed of labor income, the return on previously accumulated equity, and the return on money.

In a frictionless RBC world, the effective selling price of equity claims would be one. In the presence of search costs, however, equity claims are not fully resaleable. In this case, both the bargaining price $q$ and the effective prices $q_{v}$ and $q_{u}$ deviate from 1 . We focus on an equilibrium where $q_{v}>q>q_{u}>1$, which implies that $q_{r}<1$, i.e. entrepreneurs will be able to leverage their asset positions. We are interested in such an equilibrium, because it implies that entrepreneurs are financing constrained and liquidity frictions matter (see Proposition 1). Because the effective price of new equity claims for entrepreneurs is below the market value of equity, creating such claims is profitable for households. Therefore, they prompt entrepreneurs to spend whatever net worth they are not consuming on creating new equity. Entrepreneurs thus sell as many existing equity claims as possible and do not invest into money, i.e., $B_{u}^{\prime}=0$.

Using $B_{u}^{\prime}=0$ and noticing that $\phi_{u} q_{u}+\left(1-\phi_{u}\right) q_{r}=1$, entrepreneurs' end-of-period equity

\footnotetext{
${ }^{20}$ Notice that we implicitly impose that $S_{v}^{\prime} \geq(1-\delta)(1-\chi) S$ such that workers in a household are always buyers. Such condition is satisfied in our later numerical analysis because we focus on shocks that will not push workers to sell assets to smooth consumption. Aggregation takes into account type-specific transactions on the search market and evolutions of equity.
} 
can be rearranged from (13) as

$$
S_{u}^{\prime}=q_{r}^{-1}\left[\chi\left[r S+(1-\delta) S+\frac{B}{P}\right]-C_{u}\right],
$$

which equals their entire net worth less consumption scaled by the replacement cost $q_{r}$. For book keeping, aggregate investment $I=\frac{S_{u}^{\prime}-\left(1-\phi_{u}\right)(1-\delta) S_{u}}{1-\phi_{u}}$ can be expressed as

$$
I=\frac{\chi\left[\left(r+\phi_{u} q_{u}(1-\delta)\right) K+\frac{B}{P}\right]-C_{u}}{1-\phi_{u} q_{u}} .
$$

The Representative Household's Problem. Let $J(S, B ; \Gamma)$ be the value of the representative household with equity claims $S$ and money $B$, given the collection of aggregate state variables $\Gamma$ whose evolution is taken as given by the household. ${ }^{21}$ Since at the end of the period workers and entrepreneurs reunite to share their stocks of equity and money, we have

$$
S^{\prime}=S_{v}^{\prime}+S_{u}^{\prime}, \quad B^{\prime}=B_{v}^{\prime}+B_{u}^{\prime}
$$

Then, the value satisfies the following Bellman equation:

\section{Problem 1:}

$$
\begin{gathered}
J(S, B ; \Gamma)=\max _{\left\{N, C_{u}, C_{v}, S_{u}^{\prime}, S_{v}^{\prime}, B_{v}^{\prime}\right\}} \chi u\left(\frac{C_{u}}{\chi}\right)+(1-\chi)\left[u\left(\frac{C_{v}}{1-\chi}\right)-\mu \frac{N}{1-\chi}\right]+\beta \mathbb{E}_{\Gamma}\left[J\left(S^{\prime}, B^{\prime} ; \Gamma^{\prime}\right)\right] \\
\text { s.t. } \quad(13), \quad(14), \quad(16), \quad \text { and } \quad B_{u}^{\prime}=0
\end{gathered}
$$

We discuss the optimality conditions associated with Problem 1 in Section 3.1.

\subsection{Search, Matching, and Bargaining}

Search and Matching. Matching between buyers and sellers of private claims takes place in a decentralized market. Buyers post total asset positions $V=\phi_{v}^{-1}\left[S_{v}^{\prime}-(1-\delta) S_{v}\right]$ that are to be filled. Sellers put all their new and old assets on sale, i.e. offer $U=(1-\delta) \chi S+I$. As described earlier, the unit cost of posting asset positions and putting assets on sales are $\kappa_{u}$ and $\kappa_{v}$, respectively. We introduce a shock to the cost of financial intermediation, which in our asset search framework corresponds to an increase in these participation costs. We let

\footnotetext{
${ }^{21}$ Once we proceed to the equilibrium definition, $\Gamma \equiv\left(K, B ; z_{a}, z_{\kappa}\right)$ where $K$ is the total capital stock, $B$ is the total amount of money circulated, $z_{a}$ is total factor productivity in final goods production, and $z_{\kappa}$ is an intermediation cost shock in the search market. The exogenous stochastic processes for $z_{a}$ and $z_{\kappa}$ are specified in the numerical examples in Section 4.
} 


$$
\kappa_{u}=e^{z_{\kappa}} \bar{\kappa}_{u}, \quad \kappa_{v}=e^{z_{\kappa}} \bar{\kappa}_{v},
$$

where $z_{\kappa}$ follows an $\mathrm{AR}(1)$ process, $z_{\kappa}^{\prime}=\rho_{\kappa} z_{\kappa}+\epsilon_{\kappa}^{\prime}$, with i.i.d. $\epsilon_{\kappa}^{\prime} \sim N\left(0, \sigma_{\kappa}^{2}\right)$.

After $V$ and $U$ are determined, the number of aggregate matches $M$ is determined by the matching function

$$
M(V, U)=\xi V^{1-\eta} U^{\eta}
$$

where $\eta \in(0,1)$ is the elasticity of matches with respect to assets on sale, and $\xi$ measures matching efficiency.

Defining $\theta$ as the ratio of vacant asset positions $V$ to assets on sale $U$, we have

$$
\theta \equiv \frac{V}{U}, \quad \phi_{v} \equiv \frac{M}{V}=\xi \theta^{-\eta}, \quad \phi_{u} \equiv \frac{M}{U}=\xi \theta^{1-\eta}
$$

where $\phi_{v}$ captures the probability of a buyer meeting a seller for each unit of asset positions posted, and $\phi_{u}$ the probability of a seller meeting a buyer for each unit of assets put on sale. Recall that $\phi_{u}$ also represents the fraction of financial assets that can be sold ex post in a given period. Therefore, we refer to $\phi_{u}$ as asset resaleability or liquidity.

Notice that $\theta$ expresses the search market tightness from a buyer's perspective. A larger $\theta$ indicates that buyers have difficulty in finding appropriate investment opportunities on the search market, such that $I$ and $U$ are relatively small compared to $V$. Lastly, noticing that $\phi_{v}^{-1} \phi_{u}=\theta$, we can pin down the relationship between $\phi_{v}$ and $\phi_{u}$ as

$$
\phi_{v}=\xi^{\frac{1}{1-\eta}} \phi_{u}^{\frac{\eta}{\eta-1}}
$$

Bargaining. Once a unit of offered assets is matched to a vacancy position, individual buyers and sellers bargain over the match surplus. Following Ravn (2008) and Ebell (2011), individual agents come to bargain on behalf of their respective household. Notice that the amount of matched assets $m_{j, t}$ is predetermined at the point of bargaining. The key feature is thus that buyers and sellers interact at the margin $m_{j, t}$, i.e., the match surplus for both buyers and sellers is the respective marginal value of an additional transaction.

Denote by $J^{v}$ and $J^{u}$ the value of individual workers and entrepreneurs from the point of view of the household. Note that all members within the groups of buyers and sellers are homogeneous, such that the type-specific valuations are identical in all matched pairs. We consider the case that the transaction price $q$ is determined via Nash bargaining between a buyer and a seller, i.e. agents bargain over $q$ to maximize

$$
\max _{q}\left\{\left(J_{m}^{u}\right)^{\omega}\left(-J_{m}^{v}\right)^{1-\omega}\right\}
$$


where $\omega \in(0,1)$ is the bargaining power of sellers. We discuss the bargaining solution in Section 3.2.

A buyer's surplus amounts to ${ }^{22}$

$$
-J_{m}^{v}=-u^{\prime}\left(c_{v}\right) q+\beta \mathbb{E}_{\Gamma}\left[J_{S}\left(S^{\prime}, B^{\prime} ; \Gamma^{\prime}\right)\right]
$$

Intuitively, if the deal is agreed the buyer sacrifices $q$ today multiplied by the marginal utility of workers' consumption but gains the household value of one more unit of assets tomorrow. ${ }^{23}$ Similarly, the sellers' surplus is the marginal value to the household of an additional match for entrepreneurs

$$
J_{m}^{u}=u^{\prime}\left(c_{u}\right)\left(q-\frac{1}{\phi_{u}}\right)+\beta\left(\frac{1}{\phi_{u}}-1\right) \mathbb{E}_{\Gamma}\left[J_{S}\left(S^{\prime}, B^{\prime} ; \Gamma^{\prime}\right)\right]
$$

which says that the seller gains $\left(q-\phi_{u}^{-1}\right)$ today multiplied by the marginal utility of entrepreneurs' consumption plus a continuation value from a successful match. The contemporary surplus reflects that entrepreneurs earn the bargaining price $q$, but spend $\phi_{u}^{-1}$ resources per additional match on new investment projects. The evolution of entrepreneurs' equity position can be expressed as the difference between offered and sold assets, i.e. $s_{u}^{\prime}=u-m_{u}=\left(\phi_{u}^{-1}-1\right) m_{u}$. Thus, entrepreneurs retain a fraction $\left(\phi_{u}^{-1}-1\right)$ for each unit of successful matches as inside equity, which is brought back to the household. Therefore, the continuation value of a match consists of the marginal value of future assets to the household multiplied by this factor.

\subsection{Final Goods Producers}

On the production side, there are competitive firms which rent aggregate capital stock $K$ and hire aggregate labor $N$ from households to produce output according to

$$
Y=e^{z_{a}} F(K, N)
$$

where $F(K, N)=K^{\alpha} N^{1-\alpha}$ and $\alpha \in(0,1) . z_{a}$ measures aggregate productivity and follows a standard $\operatorname{AR}(1)$ process $z_{a}^{\prime}=\rho_{a} z_{a}+\epsilon_{a}^{\prime}$ with i.i.d random variable $\epsilon_{a} \sim N\left(0, \sigma_{a}^{2}\right)$ as an innovation. The profit-maximizing rental rate and wage rate are thus

$$
r=e^{z_{a}} F_{K}(K, N), \quad w=e^{z_{a}} F_{N}(K, N) .
$$

\footnotetext{
${ }^{22}$ The detailed derivation of agents' match surpluses is deferred to Appendix B.

${ }^{23}$ Note that search market participation costs are already sunk at the bargaining stage. However, search costs are not ignored since households take them into account when determining optimal asset posting decisions by workers and entrepreneurs.
} 


\section{Equilibrium Characterization}

\subsection{The Representative Household's Portfolio Choice}

By using the types' budget constraints to substitute out $C_{u}$ and $C_{v}$ in Problem 1 , a household's optimal choice can be reduced to the set $\left\{N, S_{u}^{\prime}, S_{v}^{\prime}, B_{v}^{\prime}\right\}$. After simplifying notation by using individuals' consumption levels, the first-order condition for labor is ${ }^{24}$

$$
u^{\prime}\left(c_{v}\right) w=\mu
$$

The first order conditions for $S_{u}^{\prime}$ and $S_{v}^{\prime}$ are

$$
u^{\prime}\left(c_{u}\right) q_{r}=\beta \mathbb{E}_{\Gamma}\left[J_{S}\left(S^{\prime}, B^{\prime} ; \Gamma^{\prime}\right)\right], \quad u^{\prime}\left(c_{v}\right) q_{v}=\beta \mathbb{E}_{\Gamma}\left[J_{S}\left(S^{\prime}, B^{\prime} ; \Gamma^{\prime}\right)\right]
$$

from which we learn that

$$
\begin{gathered}
u^{\prime}\left(c_{u}\right)=\rho u^{\prime}\left(c_{v}\right) \\
\text { where } \quad \rho \equiv \frac{q_{v}}{q_{r}} .
\end{gathered}
$$

$\rho$ is inversely related to risk-sharing among workers and entrepreneurs. When $\rho=1$, search frictions disappear and entrepreneurs are not financing constrained (see Corollary 1). In this case, (21) naturally implies $c_{u}=c_{v}$, i.e., perfect consumption risk-sharing among household members. In an economy where the search market structure imposes financing frictions, we have $\rho>1$ and therefore $c_{u}<c_{v}$ and the risk-sharing capacity of the household decreases in $\rho$. Notice that $C=C_{v}+C_{u}$, such that we have ${ }^{25}$

$$
C_{v}=\rho_{v} C, \quad C_{u}=\rho_{u} C
$$

where

$$
\rho_{v} \equiv \frac{1-\chi}{1-\chi+\rho^{-1 / \sigma} \chi}, \quad \rho_{u} \equiv \frac{\chi}{\rho^{1 / \sigma}(1-\chi)+\chi}
$$

We will use $\rho_{v}$ and $\rho_{u}$ in the subsequent analysis. Finally, the optimality condition for money holdings $B_{v}^{\prime}$ is

$$
u^{\prime}\left(c_{v}\right) \frac{1}{P}=\beta \mathbb{E}_{\Gamma}\left[J_{B}\left(S^{\prime}, B^{\prime} ; \Gamma^{\prime}\right)\right] .
$$

It is instructive to derive asset pricing formulae for equity and money corresponding to

\footnotetext{
${ }^{24}$ As in a portfolio choice problem, the corresponding first-order-conditions are also sufficient due to the concavity of the objective function.

${ }^{25} \mathrm{Using}$ the utility function $u\left(c_{j}\right)=\frac{c_{j}^{1-\sigma}-1}{1-\sigma}$ in $(21)$ and noting that $C=C_{v}+C_{u}$, we obtain $C_{v}=\rho_{v} C$ and $C_{u}=\rho_{u} C$, where $\rho_{v} \equiv \frac{1-\chi}{1-\chi+\rho^{-1 / \sigma} \chi}$ and $\rho_{u} \equiv \frac{\chi}{\rho^{1 / \sigma}(1-\chi)+\chi}$.
} 
the optimality conditions. Using the envelope condition

$$
\begin{aligned}
J_{S} & =u^{\prime}\left(c_{u}\right) \chi[r+1-\delta]+u^{\prime}\left(c_{v}\right)(1-\chi)\left[r+q_{v}(1-\delta)\right] \\
& =u^{\prime}\left(c_{v}\right)\left[(\chi \rho+1-\chi) r+(1-\delta)\left(\chi \rho+(1-\chi) q_{v}\right)\right]
\end{aligned}
$$

together with the first-order condition for equity $S_{v}^{\prime}$ we obtain

$$
\mathbb{E}_{\Gamma}\left[\frac{\beta u^{\prime}\left(\rho_{v}^{\prime} C^{\prime}\right)}{u^{\prime}\left(\rho_{v} C\right)} \frac{\left(\chi \rho^{\prime}+(1-\chi)\right) r^{\prime}+(1-\delta)\left(\chi \rho^{\prime}+(1-\chi) q_{v}^{\prime}\right)}{q_{v}}\right]=1
$$

where the second term in the expectations operator captures the internal return on equity from the perspective of the household. Similarly, we can derive another asset pricing formula for money by applying the envelope condition again

$$
\mathbb{E}_{\Gamma}\left[\frac{\beta u^{\prime}\left(\rho_{v}^{\prime} C^{\prime}\right)}{u^{\prime}\left(\rho_{v} C\right)} \frac{\chi \rho+1-\chi}{\pi^{\prime}}\right]=1,
$$

where the second term in the expectations operator is the internal return on money from the perspective of the household and inflation is defined as

$$
\pi^{\prime} \equiv \frac{P^{\prime}}{P}
$$

In the steady state, condition (24) implies that $[\chi \rho+1-\chi] \frac{1}{\pi}=\beta^{-1}$. If $\rho>1$, the real interest rate $\pi^{-1}$ will be lower than the time preference rate $\beta^{-1}{ }^{26}$ This fact shows that money may provide a liquidity service and, accordingly, carries a liquidity premium:

\section{Proposition 1:}

In the steady state

1. when $\rho>1$, nominal liquid assets provide a liquidity service. The steady state liquidity premium amounts to

$$
\Delta_{B} \equiv[\chi \rho+(1-\chi)-1] \frac{1}{\pi}=\frac{(\rho-1) \chi}{\pi}>0 .
$$

2. when $\rho=1$, the premium is zero and $\frac{\beta}{\pi}=1$.

To illustrate, when $\rho>1$, liquidity frictions bind and entrepreneurs are financing constrained. An additional unit of money then relaxes entrepreneurs' constraints by increasing

\footnotetext{
${ }^{26}$ Though we focus on fiat money such that $P^{\prime}=P$ in the steady state (and $\pi=1<\beta^{-1}$ ), one can easily imagine an economy where the government steps in and may run inflation or deflation.
} 
their net-worth, which allows them to leverage their investment or, equivalently, their future equity position, since $S_{u}^{\prime}=\left[\chi\left[r S+(1-\delta) S+\frac{B}{P}\right]-C_{u}\right] / q_{r}$ and $q_{r}<1$. Once we solve for the endogenous asset price, we will show in Corollary 1 that in the limiting case $(\rho \rightarrow 1)$ equity can be sold frictionlessly and money loses its liquidity value also off the steady state. The asset pricing formulae then collapse to standard Euler equations in a RBC model. However, if the search market is not frictionless, the liquidity premium is not zero and may vary substantially through time.

\subsection{The Bargained Asset Price}

Recall that the asset price $q$ is determined via Nash bargaining between a buyer and a seller. Equivalently, agents bargain over $q$ to maximize

$$
\omega \ln \left(J_{m}^{u}\right)+(1-\omega) \ln \left(-J_{m}^{v}\right)
$$

where $\omega \in(0,1)$ is the bargaining power of sellers. The sufficient and necessary first-order condition yields

$$
\frac{\omega}{u^{\prime}\left(c_{u}\right)\left(q-\phi_{u}^{-1}\right)+\left(\phi_{u}^{-1}-1\right) \beta \mathbb{E}_{\Gamma} J_{S}\left(S^{\prime}, B^{\prime} ; \Gamma^{\prime}\right)}=\frac{1-\omega}{-u^{\prime}\left(c_{v}\right) q+\beta \mathbb{E}_{\Gamma} J_{S}\left(S^{\prime}, B^{\prime} ; \Gamma^{\prime}\right)} .
$$

By using the household's optimality condition for asset holdings, $u^{\prime}\left(c_{v}\right) q_{v}=\beta \mathbb{E}_{\Gamma} J_{S}\left(S^{\prime}, B^{\prime} ; \Gamma^{\prime}\right)$, and the risk-sharing condition, $u^{\prime}\left(c_{u}\right)=\rho u^{\prime}\left(c_{v}\right)$, we can derive an analytical solution for the bargaining price, stated in the following proposition:

\section{Proposition 2:}

Let $\gamma$ be a collection of parameters

$$
\gamma \equiv \frac{\omega}{1-\omega} \frac{\bar{\kappa}_{v}}{\bar{\kappa}_{u}}
$$

The search market bargaining solution simplifies to

$$
\rho=\gamma \theta
$$

which can be solved for $q$ as a function of resaleability $\phi_{u}{ }^{27}$

$$
q=\frac{\gamma \phi_{u}\left(1+\frac{\kappa_{u}}{\omega}\right)-\kappa_{v}}{\xi^{\frac{1}{1-\eta}} \phi_{u}^{\frac{\eta}{\eta-1}}\left[1+\left(\gamma\left(\xi^{-1} \phi_{u}\right)^{\frac{1}{1-\eta}}-1\right) \phi_{u}\right]}
$$

\footnotetext{
${ }^{27} \mathrm{An}$ intermediate step in the derivation, which is used for simplification later, is $q=\frac{\rho\left(1+\frac{\kappa_{u}}{\omega}\right)-\frac{\kappa_{v}}{\phi_{v}}}{1+(\rho-1) \phi_{u}}$.
} 
Proof. See Appendix C.1.

Asset price and liquidity. Endogenizing asset liquidity gives rise to a non-trivial relationship between $q$ and $\phi_{u}$. Importantly, the bargaining solution (26) links the asset price $q$ to the degree of asset resaleability $\phi_{u}$. Consider some "bad shock" that reduces agents' net worth and makes current investment less attractive. Then supply on the search market will drop, because entrepreneurs have to scale down their operations; demand will also drop since the household will shift resources to other uses in view of the lower future returns to equity. If demand reduces by more than supply, resaleability $\phi_{u}$ decreases as there are fewer counterparties for sellers. If $\phi_{u}$ is small enough, the asset price also falls in response to lower investor participation as stated by Proposition 3:

\section{Proposition 3:}

$q$ correlates positively with asset resaleability $\phi_{u}$ (i.e. $\frac{\partial q}{\partial \phi_{u}}>0$ ) and negatively with the purchase rate $\phi_{v}$ (i.e. $\frac{\partial q}{\partial \phi_{v}}<0$ ), if and only if ${ }^{28}$

$$
\phi_{u}<\left[\frac{\eta}{1-\eta}+\left(1+\frac{\kappa_{u}}{\omega}\right) \frac{\rho}{q}\right]\left[\frac{\eta}{1-\eta}+2 \rho-1\right]^{-1} \equiv \bar{\phi}_{u}
$$

Proof. See Appendix C.2.

Intuitively, the drop in resaleability implies that a larger share of investment needs to be financed out of entrepreneurs' own funds. On one hand, this tightens the contemporaneous financing constraints of bargaining entrepreneurs. The threat point for entrepreneurs of breaking off negotiations over an additional asset sale and self-financing at the margin becomes less attractive. Entrepreneurs are thus more willing to accept a smaller bargaining price. On the other hand, retaining a larger fraction of equity stakes also implies that entrepreneurs return more assets to the household, which relaxes the funding constraints of future generations of entrepreneurs. This effect supports the threat point, such that entrepreneurs ask for a higher transaction price in a successful match. Thus, a trade-off emerges between current and future funding constraints.

Proposition 3 shows that the contemporaneous effect dominates as long as the sales rate is small enough, because current financial constraints bind strongly. Provided that financial frictions are sufficiently tight, our model can thus generate simultaneous decreases in asset liquidity and the asset price through the simultaneous reaction of supply and demand.

\footnotetext{
${ }^{28}$ Note that $\bar{\phi}_{u}$ will be close to one in any reasonable calibration, since $\frac{\kappa_{u}}{\omega}$ is small and both $\rho$ and $q$ are above, but close to one. In fact, when search costs go to zero we have $\rho \rightarrow 1$ and $q \rightarrow 1$ as shown in Corollary 1. In this case, also $\bar{\phi}_{u} \rightarrow 1$. Therefore, the above condition is easily satisfied by reasonably calibrated models with small search costs.
} 
In contrast, an exogenous drop in asset resaleability, such as in KM and Shi (2012), acts like a negative supply shock on the asset market: The decline in resaleability translates into a tighter financing constraint for entrepreneurs and less supply of financial claims on the asset market. However, the productivity of capital is not affected by the shock such that asset demand does not fall. The dominating supply contraction triggers an asset prices boom - a counter-factual phenomenon in recessions. Although this effect is still present in our framework, there are competing forces from the demand side that usually outweigh the supply contraction as argued before.

Frictionless limiting case. Finally, we can link our model to an economy without search frictions using our closed form solutions. When there are no search costs for either buyers or sellers, i.e. $\kappa_{v}=0$ and $\kappa_{u}=0$, the search market price will go to $q=1$, because there is no asset supply shortage. In this case, money loses its liquidity premium and the economy collapses to the RBC framework.

\section{Corollary 1:}

When $\kappa_{v}, \kappa_{u} \rightarrow 0$,

1. $q_{v} \rightarrow q_{u} \rightarrow q \rightarrow 1$ and $\rho \rightarrow 1$

2. asset pricing formulae (23) and (24) reduce to standard consumption Euler equations

$$
\mathbb{E}_{\Gamma}\left[\frac{\beta u^{\prime}\left(c_{v}^{\prime}\right)}{u^{\prime}\left(c_{v}\right)}(r+1-\delta)\right]=1, \quad \mathbb{E}_{\Gamma}\left[\frac{\beta u^{\prime}\left(c_{v}^{\prime}\right)}{u^{\prime}\left(c_{v}\right)} \frac{1}{\pi^{\prime}}\right]=1
$$

3. $\theta \rightarrow \frac{1-\omega}{\omega}, \phi_{u} \rightarrow \xi\left(\frac{1-\omega}{\omega}\right)^{1-\eta}$, and $\phi_{v} \rightarrow \xi\left(\frac{1-\omega}{\omega}\right)^{-\eta}$.

Proof. See Appendix C.3.

\subsection{Recursive Competitive Equilibrium}

Before defining the competitive equilibrium we make a few additional simplifications. We first embed the capital market clearing condition:

$$
S=K, \quad S^{\prime}=K^{\prime}
$$

Second, we reduce the number of endogenous variables by eliminating $q, q_{u}$, and $\phi_{v}$. To that end, we use the bargaining solution for $q$ from the intermediate step in Proposition 2 and 
rewrite $q_{v}=q+\kappa_{v} / \phi_{v}$ as

$$
q_{v}=\frac{\rho\left[\left(1+\frac{\kappa_{u}}{\omega}\right)+(\rho-1) \kappa_{v} \gamma^{-1}\right]}{1+(\rho-1) \phi_{u}}=\frac{\rho\left[1+\kappa_{u}+\rho \frac{(1-\omega) \kappa_{u}}{\omega}\right]}{1+(\rho-1) \phi_{u}} .
$$

Noticing that $\frac{\phi_{u}}{\phi_{v}}=\gamma^{-1} \rho$ and using equation (18), $\phi_{v}$ can be eliminated and asset liquidity can be expressed as

$$
\phi_{u}=\xi\left(\gamma^{-1} \rho\right)^{1-\eta}
$$

The effective selling price then becomes

$$
q_{u}=q-\frac{\kappa_{u}}{\phi_{u}}=q_{v}-\left[\frac{(1-\omega) \rho}{\omega}+1\right] \frac{\kappa_{u}}{\phi_{u}}
$$

Next, we can express $\rho=q_{v} / q_{r}$ as

$$
\rho=\frac{\left(1-\phi_{u}\right) q_{v}}{\left(1-\phi_{u}\right) q_{u}}=\frac{\left(1-\phi_{u}\right) q_{v}}{1-\phi_{u} q_{v}+\left[\omega^{-1}(1-\omega) \rho+1\right] \kappa_{u}}
$$

Summing over the type-specific budget constraints (13) and (14) (and noting that $S=S_{u}+S_{v}$ and $B=B_{u}+B_{v}$ ), we derive the household budget constraint ${ }^{29}$

$$
\begin{aligned}
\left(\rho_{v}+\rho \rho_{u}\right) C+q_{v} K^{\prime}+\frac{B^{\prime}}{P}= & w N+\left[(\chi \rho+1-\chi) r+(1-\delta)\left(\chi \rho+(1-\chi) q_{v}\right)\right] K \\
& +[\chi \rho+(1-\chi)] \frac{B}{P}
\end{aligned}
$$

Finally, recall that aggregate investment is given by

$$
I=\frac{\chi\left[\left(r+\phi_{u} q_{u}(1-\delta)\right) K+\frac{B}{P}\right]-\rho_{u} C}{1-\phi_{u} q_{u}}=\frac{\chi\left[\left(r+\phi_{u} q_{u}(1-\delta)\right) K+\frac{B}{P}\right]-\rho_{u} C}{1-\phi_{u} q_{v}+\left[\frac{\omega^{-1}(1-\omega) \rho}{+} 1\right] \kappa_{u}}
$$

\section{Definition 1:}

The recursive competitive equilibrium is a mapping $\left(K, z_{a}, z_{\kappa}\right) \rightarrow\left(K^{\prime}, z_{a}^{\prime}, z_{\kappa}^{\prime}\right)$, with associated consumption, investment, labor, and portfolio choices $\left\{C, I, N, B^{\prime}, K^{\prime}\right\}$, asset liquidity $\left\{\phi_{u}\right\}$, , a collection of prices $\left\{P, q_{v}, \rho, w, r\right\}$, and the evolution of $\left\{z_{a}, z_{\kappa}\right\}$, where

1. households' optimality conditions: given prices, the policy functions solve the representative household's problems, i.e., (20), (23), and (24) are satisfied; investment is given by (31);

\footnotetext{
${ }^{29}$ When $\rho=1, q_{v}=q_{u}=q=1$, such that financial frictions are eliminated. In this case, the household budget constraint collapses to a standard budget constraint $C+S^{\prime}+\frac{B^{\prime}}{P}=w N+[r+(1-\delta)] S+\frac{B}{P}$.
} 
2. goods producers' optimality conditions: (19);

3. market clearing conditions:

(a) the household-wide budget constraint (30) is satisfied,

(b) the capital market clears, i.e. $K^{\prime}=(1-\delta) K+I$,

(c) the search market clears, i.e., (28) holds; the effective buying price qv satisfies (27) and the measure of risk-sharing between buyers and sellers $\rho$ (related to search intensity) is given by (29),

(d) the market for liquid assets clears, i.e. $B^{\prime}=B$;

4. exogenous productivity and intermediation costs evolve according to $z_{a}^{\prime}=\rho_{a} z_{a}+\epsilon_{a}^{\prime}$ and $z_{\kappa}^{\prime}=\rho_{\kappa} z_{\kappa}+\epsilon_{\kappa}^{\prime}$.

To verify that Walras' Law is satisfied, notice that the investment equation and the household budget constraint resemble the entrepreneurs' and workers' budget constraints (13) and (14). These two constraints imply that the aggregate resource constraint is ${ }^{30}$

$$
C+I+\kappa_{v} V+\kappa_{u} U=e^{z_{\alpha}} K^{\alpha} N^{1-\alpha},
$$

where $U$ and $V$ are the total number of assets on sale and asset positions to be filled. Finally, in our subsequent numerical analysis, we refer to investment as the sum of $I, \kappa_{v} V$, and $\kappa_{u} U$.

\subsection{The Social Planner's Problem}

The search market structure of our asset market may give rise to congestion externalities. In particular, the decision to enter the market from either seller or buyer side will tighten - or congest - the market for all sellers or buyers, thereby decreasing individual matching probabilities. Search externalities feed into the bargaining price via search market tightness $\theta$ and thus affect relative prices and the portfolio choices. In order to analyze how externalities affect the decentralized equilibrium, we now consider the social planner solution that internalizes search frictions. The social planner may want to choose different search intensities (search market tightness) $\theta_{t}$ (or equivalently $\rho$ as shown in Proposition 2 ) in order to maximize the household's welfare, such as in Rogerson and Shimer (2011).

\footnotetext{
${ }^{30}$ To see this, we add households budget constraint (14) and (13) which gives

$$
C+q_{v}\left[S_{v}^{\prime}-(1-\delta) S_{v}\right]+\left[q_{r} S_{u}^{\prime}-(1-\delta) S_{u}\right]=Y .
$$

Plugging in $S_{v}^{\prime}-(1-\delta) S_{v}=\phi_{v} V$ and $S_{u}^{\prime}=\left(1-\phi_{u}\right)\left[(1-\delta) S_{u}+I\right]=\left(1-\phi_{u}\right) U$, one can obtain the aggregate resources constraint (32).
} 
As the first step, we derive the social resource constraint related to $\rho$. Since $U=$ $(1-\delta) \chi K+I$ and $I=K^{\prime}-(1-\delta) K$, we can express asset supply and demand on the search market as $U=K^{\prime}-(1-\chi)(1-\delta) K$ and $V=\theta U$. By substituting $U$ and $V$ out, one can rewrite the aggregate resources constraint (32) as

$$
C+\left(1+\kappa_{v} \gamma^{-1} \rho+\kappa_{u}\right) K^{\prime}=e^{z_{\alpha}} K^{\alpha} N^{1-\alpha}+\left(1+\kappa_{v} \gamma^{-1} \rho+\kappa_{u}\right)(1-\chi)(1-\delta) K
$$

But the planner's problem is complicated by the presence of capital accumulation and the endogenous prices of liquid assets and private claims. Asset prices are endogenous functions of the policy variable $\rho$. Drawing on insights from the optimal taxation literature (see for example Chari and Kehoe (1999) and more recently Bhandari, Evans, Golosov, and Sargent (2013)), we use individual optimality conditions for assets and labor as well as the representative household's budget constraint to derive one simple analytical "implementability condition" which depends on allocations of consumption, labor, and initial asset positions, but not on asset prices and future asset stocks. The social planner will then maximize total utility subject to this implementability condition and the aggregate resource constraint (33). Since the social planner solution respects individual constraints and choices through the implementability condition, it is consistent with individual behavior in the decentralized economy.

To avoid complicating our main discussion, we leave the details of the implementability condition and the planner's problem to Appendix E. A general message from the exercise is that individuals in the decentralized economy ignore the externality that their search market participation exerts on entrepreneurs' financing conditions. For our preferred numerical example in the next session, the social planner would, in fact, choose a higher degree of search intensity, which implies higher asset liquidity and more relaxed financing constraints for entrepreneurs. ${ }^{31}$ However, any attempt to implement the optimal search intensity through taxation or asset purchase programs might be complicated by unintended side-effects, such as crowding-out private investors from the asset market. Having said that, we leave the design of optimal policy to future research.

Finally, as also shown in the Appendix, the efficiency of the decentralized economy depends on the institutional design of the search market, i.e. the bargaining power of the sellers or the supply elasticity of matches. We capture this result in a modified "Hosios" condition adapted to our search framework.

\footnotetext{
${ }^{31}$ For simplicity, we do not address implementation through taxation and monetary policy (which may include unconventional monetary policy measures). That is, we do not discuss the policy instruments that should be deployed to achieve the constrained efficient outcome in the decentralized economy. The implementation is slightly more complicated and requires the alternative setup with interest bearing government bonds and taxation. However, the basic logic of deriving the "implementability condition" would still hold.
} 


\section{Numerical Examples}

\subsection{Calibration}

We target quarterly frequency and choose those parameters that are not related to the search market by following a conventional calibration, such as targeting the investment-toGDP ratio (see Table 2). Note that the parameter $\chi$ can be interpreted as the fraction of firms which adjust capital in a period. According to Doms and Dunne (1998), the annual fraction is 0.20 which translates to $\chi=0.055$ in quarterly frequency.

Table 2: Baseline calibration

\begin{tabular}{lrll}
\hline & Parameter & Baseline Value & Target/Source \\
\hline Preferences and Production Technology & & & \\
Household discount factor & $\beta$ & 0.9900 & exogenous \\
Relative risk aversion & $\sigma$ & 2 & exogenous \\
Utility weight on leisure & $\mu$ & 3.6798 & working time: $33 \%$ \\
Mass of entrepreneurs & $\chi$ & 0.0550 & Doms and Dunne $(1998)$ \\
Depreciation rate of capital & $\delta$ & 0.0250 & exogenous \\
Capital share of output & $\alpha$ & 0.2955 & Investment-to-GDP ratio: $20.8 \%$ \\
Search and Matching & & & \\
Matching efficiency & $\xi$ & 0.5178 & liquidity ratio: $B / Y=30.0 \%$ \\
Buyer search costs & $\bar{\kappa}_{v}$ & 0.0199 & unit cost: $\frac{\kappa_{v}}{\phi_{v} q}=2 \%$ \\
Seller search costs & $\bar{\kappa}_{u}$ & 0.0067 & unit cost: $\frac{\kappa_{u}}{\phi_{u} q}=2 \%$ \\
Supply sensitivity of matching & $\eta$ & 0.5000 & exogenous \\
Bargaining weight of sellers & $\omega$ & 0.5421 & Tobins $q=1.1$ \\
Shock Processes & & & \\
Persistence, productivity shock & $\rho_{z}$ & $0.8598(0.0306)$ & estimated \\
Persistence, cost shock & $\rho_{\kappa}$ & $0.8322(0.0184)$ & estimated \\
Std. dev., productivity shock & $\sigma_{z}$ & $0.0078(0.0004)$ & estimated \\
Std. dev., cost shock & $\sigma_{\kappa}$ & $1.3380(0.0907)$ & estimated \\
\hline
\end{tabular}

Notes: The model is calibrated to quarterly frequency. Standard errors of estimated parameters are in brackets.

There are five search-market related parameters $\left\{\xi, \bar{\kappa}_{v}, \bar{\kappa}_{u}, \eta, \omega\right\}$. Due to the constant returns to scale matching technology on the search market, $\xi$ and $\eta$ are not independent. Without loss of generality, we set $\eta=0.5$ and calibrate $\xi$. We further tie our hands by choosing the same value for the unit cost of search market participation from both buyer and seller perspective, $\bar{\kappa}_{v}$ and $\bar{\kappa}_{v}$. We are then left with three independent parameters, which we calibrate to match three steady state targets: Tobin's $q$, the liquidity ratio, and the average cost of the intermediation of financial assets. Tobin's $q$ ranges from 1.1 to 1.21 in the U.S. economy according to Compustat data. The liquidity ratio, defined as the total amount of nominal liquid assets (essentially money and government bonds, see details in Appendix A) circulated in the U.S. over total nominal GDP, is $30 \%$ on average over the sample periods. Finally, the unit cost of intermediating financial assets through either financial institutions or markets is about $2 \%$ according to Philippon (2013). 


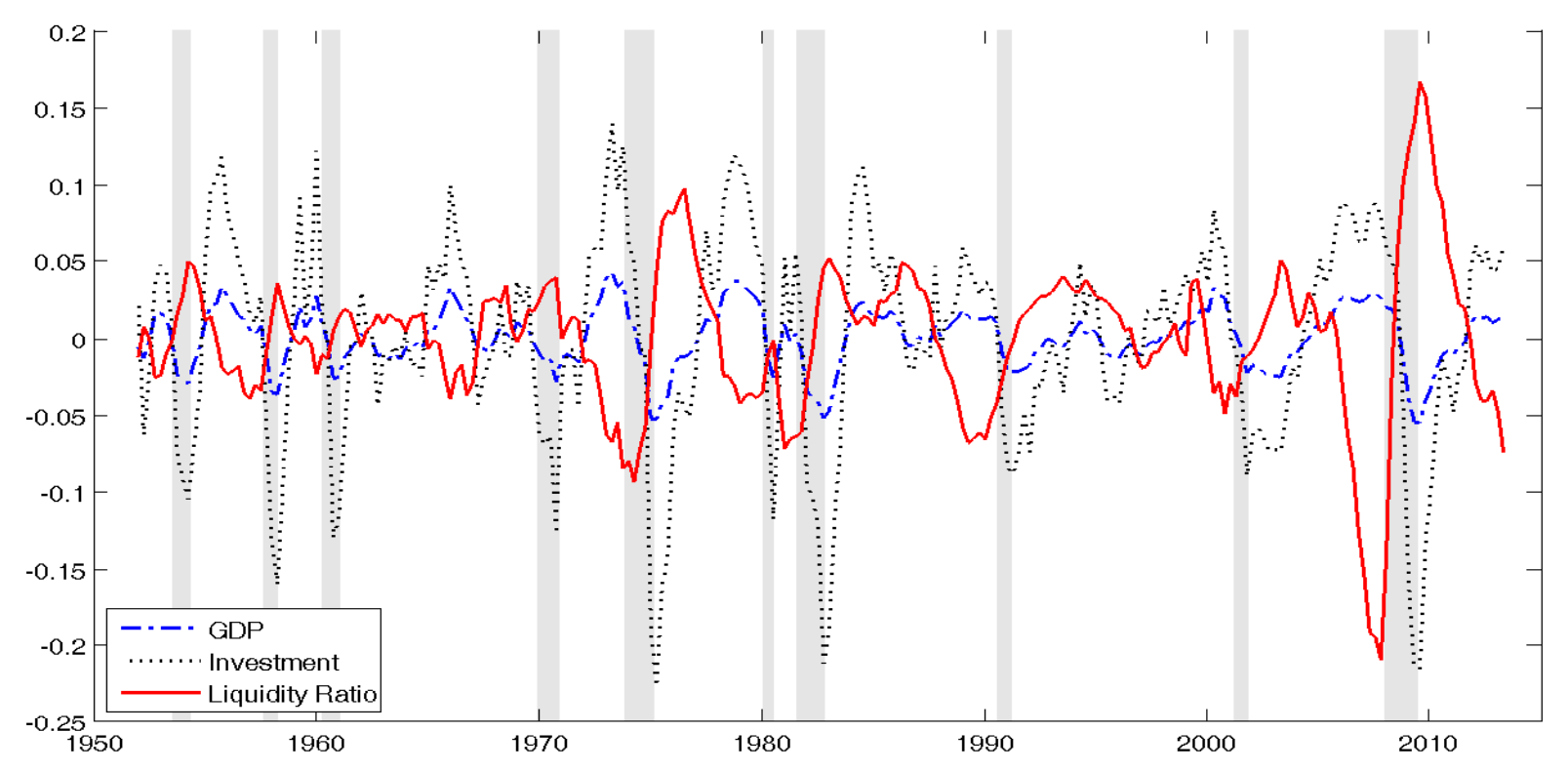

Figure 1: Real GDP, investment and the liquidity ratio

The plotted time series are deviations from the HP filtered trend. Real GDP is the sum of real consumption and real private investment. The liquidity ratio is the ratio of nominal liquid assets over nominal (total) GDP. Liquid assets consist of all domestically held liabilities of the federal government (see Appendix A). All series are seasonally adjusted. Shaded areas denote NBER recessions dates. Source: U.S. Flow of funds and NIPA 1952Q1 to 2013Q2.

To approximate the solution to the non-linear model, we log-linearize the system around the deterministic steady state. We then estimate the shock processes using data for real GDP (consumption + private investment) and the liquidity ratio. Our measure of the liquidity ratio is intended to capture the private sector's incentive to hold liquid assets. In order to make this measure robust to supply-driven expansions of the stock of liquid assets, we normalize it by total GDP, which includes government expenditure financed by debt issuance. Notice that the correlation between the cyclical components of real GDP and the liquidity ratio is highly negative in the U.S. (-0.60) and so is the correlation between investment and the liquidity ratio $(-0.58)$ as shown in Figure 1 . To complete the calibration, we use the maximum likelihood estimators of the persistence and standard deviation of our shock processes. All estimates are significant at the $1 \%$ level (see Table 2).

Some key business cycle statistics of the model in comparison to the data are reported in Table 3. While our model generally produces more investment and liquidity ratio volatility relative to GDP than observed in the data, the pattern across different variables is similar. Importantly, our model matches the negative correlation between GDP and the liquidity ratio. In order to improve our understanding of the underlying model dynamics, we now turn to the impulse responses to productivity and intermediation cost shocks. 
Table 3: Cycle statistics

\begin{tabular}{|c|c|c|c|c|c|c|}
\hline \multirow[b]{2}{*}{ Variable $x$} & \multicolumn{2}{|c|}{ Relative volatility $\frac{\sigma_{x}}{\sigma_{y}}$} & \multicolumn{2}{|c|}{ Correlation $\rho(x, y)$} & \multicolumn{2}{|c|}{ 1st auto-correlation } \\
\hline & Data & Model & Data & Model & Data & Model \\
\hline Output & 0.02 & 0.02 & 1.00 & 1.00 & 0.88 & 0.89 \\
\hline Investment & 3.52 & 3.44 & 0.96 & 0.76 & 0.82 & 0.81 \\
\hline Liquidity Ratio & 2.84 & 3.35 & -0.60 & -0.62 & 0.92 & 0.96 \\
\hline
\end{tabular}

Note: The volatility of output $(y)$ is reported as is. The relative volatilities and correlations of other variables are measured against $y$.

\subsection{Total Productivity (TFP) Shock}

A negative one standard deviation $(0.78 \%)$ total productivity shock depresses the rental rate of capital and its value to the household. Accordingly, the total match surplus to be bargained over on the search market shrinks. This makes search for investment into entrepreneurs less attractive and the amount of purchase orders from workers drops. The demand-driven fall in the number of matches is reflected in the sharp drop in asset resaleability $\phi_{u}$ (Figure 2). This endogenous decline of asset liquidity amplifies the initial shock in two ways: (1) it reduces the quantity of assets that entrepreneurs are able to sell; (2) the bargaining price, i.e. private assets' resale value falls - though only modestly - in line with our analytical result in Proposition 3. Both effects constrain the flow of liquid funds to entrepreneurs and thus tighten their financing constraints. As a result, investment falls strongly.

In principle, money's liquidity service becomes more valuable to households when private claims' liquidity declines. However, in the case of a persistent TFP shock lower expected returns to capital make future investment less attractive. This effect works against the incentive to hedge against asset illiquidity. Which effect dominates depends on the calibration and is thus an empirical question. In our calibration, the profitability of investment projects falls sufficiently for the liquidity ratio to drop. To the extent that total factor productivity reverts back to the steady state while asset liquidity is still subdued, hedging becomes more attractive which explains the relatively fast recovery of the liquidity ratio.

Note that our economy contrasts sharply with a frictionless RBC model. In our framework, the liquidity (resaleability) of financial assets is endogenously generated through the features of the search market. In the absence of search frictions, these liquidity effects would not occur after adverse shocks. In a RBC world, negative TFP shocks primarily affect the demand for capital goods and thus reduce the optimal level of investment. In addition to this effect, entrepreneurs are financing constrained in our model, which strongly amplifies the response of investment as argued above. 

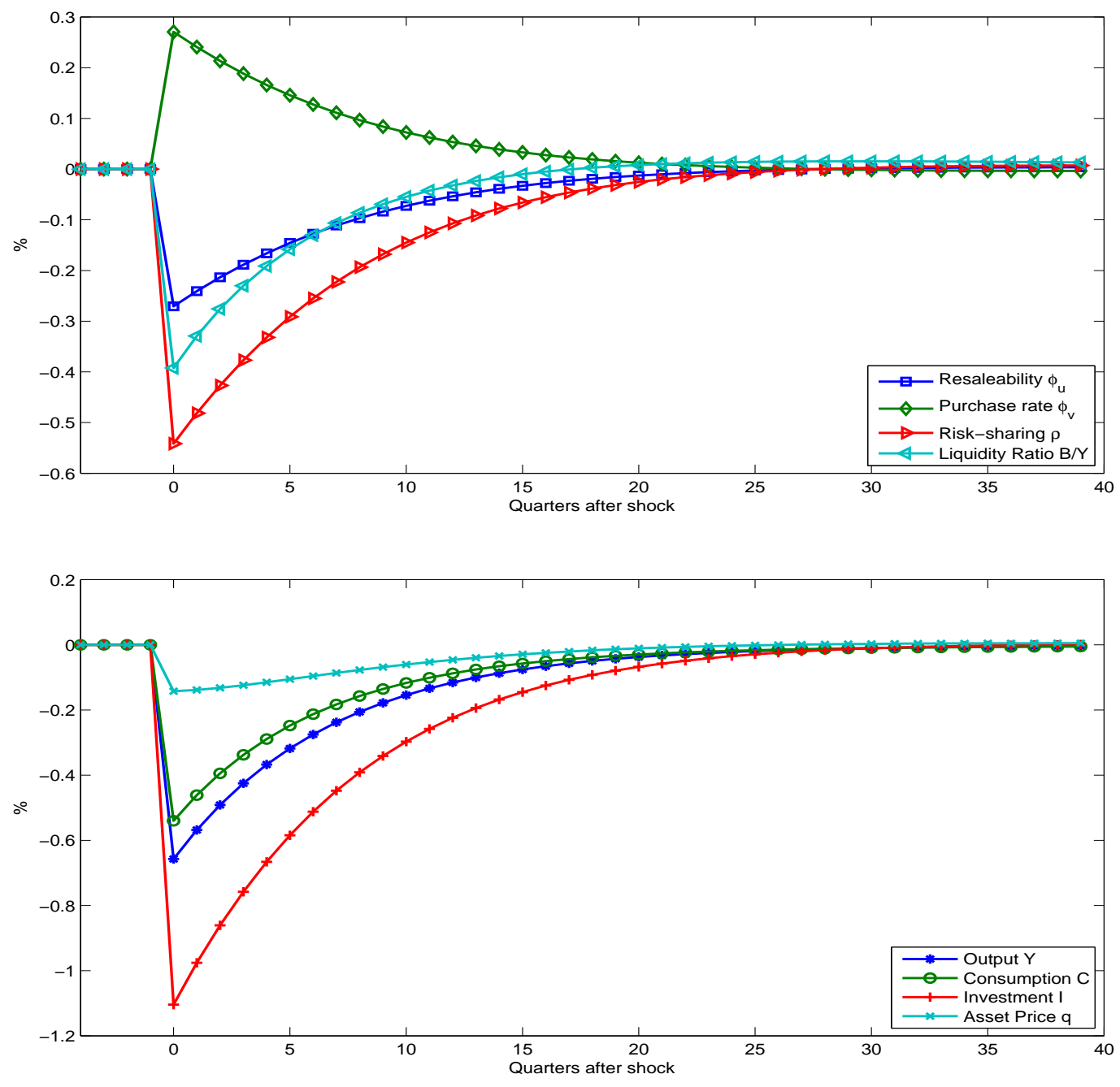

Figure 2: Impulse responses after a negative one standard deviation productivity shock.

\subsection{Intermediation Cost Shock}

In order to characterize the impact of asset search frictions on the dynamic behavior of our economy, we model an increase in the cost of search market participation, which is symmetric for sellers and buyers. Rather than affecting the production frontier of the economy, this shock simply impairs the capacity of the search market to intermediate funds between workers and entrepreneurs and, thus, unfolds its effects solely through asset prices and liquidity.

Higher search costs (one standard deviation 1.34\%) immediately depress the effective sales price of private claims, while raising their effective purchase price. In addition, higher search costs bind resources. Both the substitution and the income effect induce households to adjust their portfolios. Realizing that search market participation is more costly now and in the future, households seek to reduce their exposure to private financial claims. On 

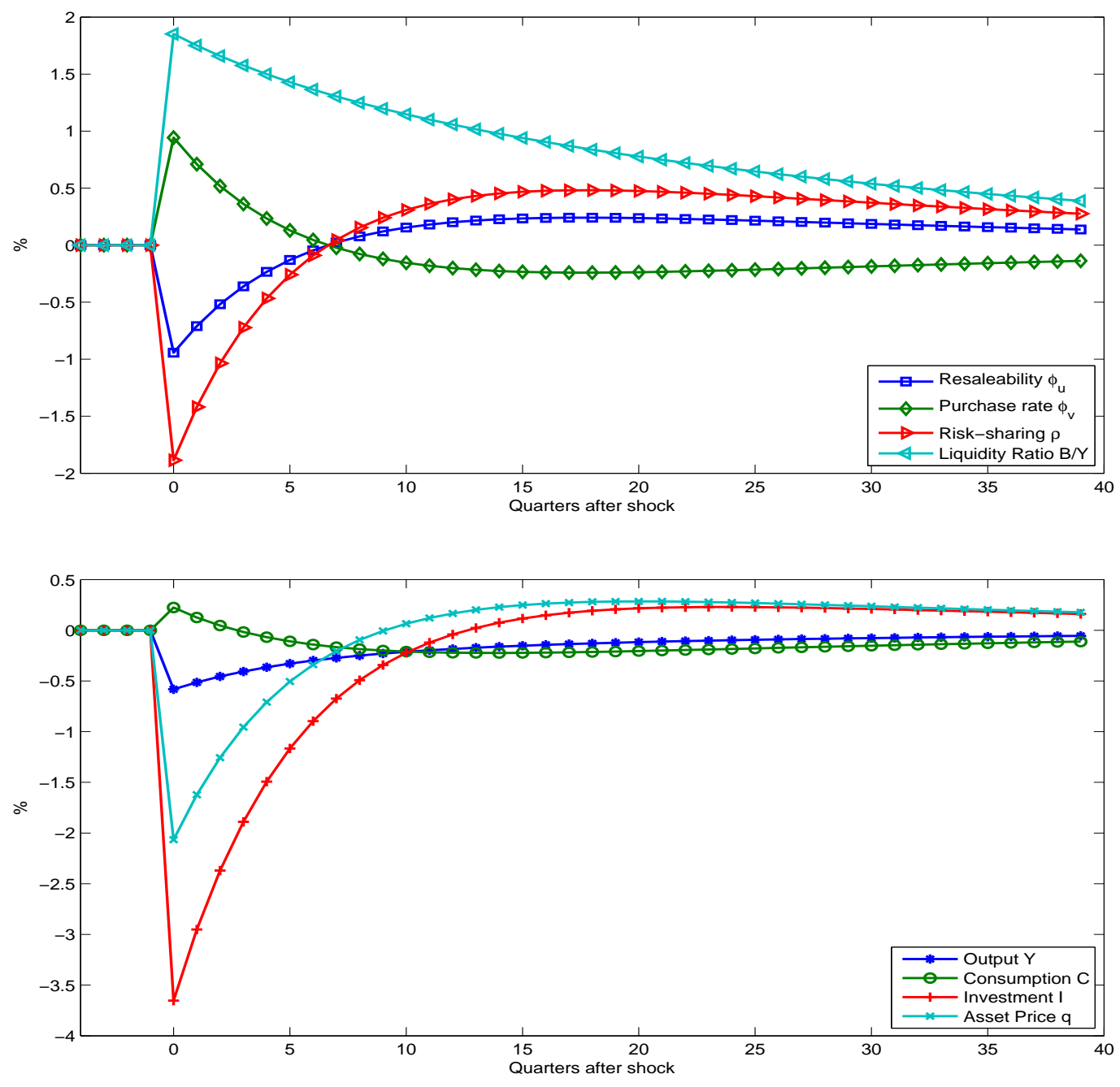

Figure 3: Impulse responses after a positive one standard deviation intermediation cost shock.

the supply side, though less investment can be issued, financing-constrained entrepreneurs still want to sell as many assets as possible in order to take full advantage of profitable investment opportunities. Asset demand on the search market thus shrinks relative to asset supply, which depresses asset resaleability while improving the purchase rate (see Figure 3).

Since the sharp drop in asset liquidity tightens entrepreneurs financing constraints substantially, the threat point of abandoning the bargaining process with a potential buyer worsens. Entrepreneurs as sellers are willing to accept a lower price. The bargaining price thus falls strongly and amplifies the initial shock by depressing entrepreneurs' net worth further. This effect is mirrored in a significant decline of investment activity, the impact response of which is about six times stronger than that of output.

While the intermediation cost shock depresses the demand for and liquidity of private 
assets, it substantially increases the hedging value of money. To see this, note that future investment remains profitable since the productivity of capital is not affected by the shock. To take advantage of future investment opportunities, households seek to hedge against the persistent illiquidity of private claims by expanding their liquidity holdings. This motive consequently drives up the liquidity ratio in line with the data.

As asset prices fall, households become inclined to raise consumption. In particular, they react to the impaired transmission of funds by reducing the discrepancy in relative consumption levels of workers and entrepreneurs. Accordingly, risk-sharing improves as captured by a decrease in $\rho$.

Summary. The dynamic behavior of our economy suggests two key results. (1) In order to reconcile declining asset liquidity with falling asset prices, liquidity must be an endogenous phenomenon. In other words, it must be a consequence, rather than a cause of economic disturbances. (2) Both standard productivity and genuine search market shocks affect the hedging value of liquid assets. However, only the latter unambiguously implies a countercyclical liquidity ratio as observed in the data.

\section{Conclusion}

We endogenize asset liquidity in a macroeconomic model with search frictions. Endogenous fluctuation of asset liquidity may be triggered by shocks that affect asset demand and supply on the search market either directly (intermediation cost shock), or indirectly (productivity shock). By tightening entrepreneurs' financing constraints, they feed into investment, consumption and output. Interpreting liquidity as asset resaleability, we show that asset prices co-move with liquidity in a reasonably calibrated model. The endogenous nature of asset liquidity is key to match this pro-cyclicality, as exogenous liquidity shocks would act as negative supply shocks on the asset market and lead to higher asset prices in recessions.

We also show that the liquidity service provided by intrinsically worthless governmentissued assets, such as money, is higher when financing constraints bind tightly. As a result, shocks to the cost of financial intermediation increase the hedging value of liquid assets, enabling our model to replicate the "flight to liquidity" or countercyclical ratio of liquid assets relative to GDP observed in the U.S. data.

Our search framework can be interpreted as a model of market-based financial intermediation. It can, however, also be seen as a short-cut to model bank-based financial intermediation: financial intermediaries help channel funds from investors to suitable creditors in need of outside funding, a process which resembles a matching process. Adding further texture by explicitly accounting for intermediaries' balance sheets would open interesting interactions 
between liquidity cycles and financial sector leverage and maturity transformation.

Regarding government interventions, our framework suggests that, as in KM, open market operations in the form of asset purchase programs can have real effects by easing liquidity frictions. However, we highlight that with endogenous liquidity such policies need to be carefully designed, because of potential crowding-out effects on the private market participants. Future research could focus on the optimal design of conventional and unconventional monetary as well as fiscal policy measures in the presence of illiquid asset markets.

\section{References}

Acemoglu, D., and R. Shimer (1999): "Efficient Unemployment Insurance," Journal of Political Economy, 107(5), 893-928.

Ajello, A. (2012): "Financial Intermediation, Investment Dynamics and Business Cycle Fluctuations," wokring paper, Federal Reserve Board.

Anderson, R. G., And C. S. Gascon (2009): "The Commercial Paper Market, the Fed, and the 2007-2009 Financial Crisis," Federal Reserve Bank of St. Louis Review, 91(6), 589-612.

Ashcraft, A. B., And D. Duffie (2007): "Systemic Illiquidity in the Federal Funds Market," AEA Papers and Proceedings, 97(2), 221-25.

BaO, J., J. PAn, And J. WAng (2011): "The Illiquidity of Corporate Bonds," Journal of Finance, 66(3), 911-946.

Beaubrun-Diant, K. E., And F. Tripier (2013): "Search Frictions, Credit Market Liquidity, and Net Interest Margin Cyclicality," working paper, CEPII.

Bhandari, A., D. Evans, M. Golosov, and T. J. Sargent (2013): "Taxes, Debts, and Redistributions with Aggregate Shocks," NBER Working Paper.

Chari, V. V., And P. J. Kehoe (1999): "Optimal Fiscal and Monetary Policy," in Handbook of Macroeconomics, ed. by J. B. Taylor, and M. Woodford, vol. 1, chap. 26. Elsevier Science B.V.

Chordia, T., R. Roll, and A. Subrahmanyam (2001): "Market Liquidity and Trading Activity," The Journal of Finance, 56(2), 501-530.

Chordia, T., A. Sarkar, and A. Subrahmanyam (2005): "An Empirical Analysis of Stock and Bond Market Liquidity," Review of Financial Studies, 18(1), 85-129. 
Christiano, L. J., R. Motto, and M. Rostagno (2014): "Risk Shocks," American Economic Review, 104(1), 27-65.

Cui, W. (2013): "Delayed Capital Reallocation," working paper, University College London.

Del Negro, M., G. Eggertsson, A. Ferrero, and N. Kiyotaki (2011): "The Great Escape? A Quantitative Evaluation of the Fed's Liquidity Facilities," Federal Reserve Bank of New York Staff Report, 520.

Diamond, P. A. (1982): "Wage Determination and Efficiency in Search Equilibrium," The Review of Economic Studies, 49(2), 217-27.

Dick-Nielsen, J., P. Feldhütter, and D. Lando (2012): "Corporate bond liquidity before and after the onset of the subprime crisis," Journal of Financial Economics, 103(3), 471-492.

Doms, M., And T. Dunne (1998): "Capital Adjustment Patters in Manufacturing Plants," Review of Economic Dynamics, 1, 409-429.

Duffie, D., N. GÂrleanu, and L. H. Pedersen (2005): "Over-the-counter markets," Econometrica, 73(6), 1815-1847.

(2007): "Valuation in Over-the-Counter Markets," Review of Financial Studies, 20(6), 1865-1900.

EBell, M. (2011): "On the cyclicality of unemployment: Resurrecting the participation margin," Labour Economics, 18(6), 822-836.

Eisfeldt, A. L. (2004): "Endogenous Liquidity in Asset Markets," Journal of Finance, $59(1), 1-30$.

Eisfeldt, A. L., And A. A. Rampini (2009): "Financing Shortfalls and the Value of Aggregate Liquidty," working paper, UCLA and Duke University.

Feldhutter, P. (2011): "The Same Bond at Different Prices: Identifying Search Frictions and Selling Pressures," Review of Financial Studies, 25(4), 1155-1206.

Gorton, G., And A. Metrick (2012): "Securitized banking and the run on repo," Journal of Financial Economics, 104(3), 425-451.

Guerrieri, V., And R. Shimer (2012): "Dynamic Adverse Selection: A Theory of Illiquidity, Fire Sales, and Flight to Quality," NBER Working Paper, 17876. 
Haan, W. J. D., G. Ramey, and J. Watson (2003): "Liquidity flows and fragility of business enterprises," Journal of Monetary Economics, 50(6), 1215-1241.

Huberman, G., And D. Halka (2001): "Systematic Liquidity," Journal of Financial Research, 24(2), 161-178.

JaCCARD, I. (2013): "Liquidity Constraints, Risk Premia, and the Macroeconomic Effects of Liquidity Shocks," ECB working paper, 1525.

Jermann, U., ANd V. QuAdrini (2012): "Macroeconomic Effects of Financial Shocks," American Economic Review, 102(1), 238-271.

KARA, E., AND J. SIN (2013): "Liquidity, Quantitative Easing and Optimal Monetary Policy," working paper, University of Bristol.

Keynes, J. M. (1936): The General Theory of Employment, Interest and Money. Macmillan Cambridge University Press.

Kiyotaki, N., And J. Moore (2012): "Liquidity, Business Cycles, and Monetary Policy," NBER Working Paper, 17934.

Kurlat, P. (2013): "Lemons Markets and the Transmission of Aggregate Shocks," American Economic Review, 103(4), 1463-1489.

Lagos, R., and G. Rocheteau (2008): "Money and capital as competing media of exchange," Journal of Economic Theory, 142(1), 247-258.

(2009): "Liquidity in Asset Markets With Search Frictions," Econometrica, 77(2), $403-426$.

Lagos, R., And R. Wright (2005): "A Unified Framework for Monetary Theory and Policy Analysis," Journal of Political Economy, 113(3), 463-484.

LuCAs, R. E. (1990): "Liquidity and interest rates," Journal of Economic Theory, 50(2), $237-264$.

Lucas, R. J., And N. L. Stokey (1983): "Optimal fiscal and monetary policy in an economy without capital," Journal of Monetary Economics, 12(1), 55-93.

Mortensen, D. T., and C. A. Pissarides (1994): "Job creation and job destruction in the theory of unemployment," The Review of Economic Studies, 61(3), 397-415. 
Petrosky-Nadeau, N., and E. Wasmer (2013): "The cyclical volatility of labor markets under frictional financial markets," American Economic Journal: Macroeconomics, 5(1), $1-31$.

Philippon, T. (2013): "Has the U.S. Finance Industry Become Less Efficient? On the Theory and Measurement of Financial Intermediation," working paper, New York University.

Ravn, M. O. (2008): "The Consumption-Tightness Puzzle," NBER International Seminar on Macroeconomics 2006, pp. 9-63.

Rocheteau, G., and R. Wright (2005): "Money in search equilibrium, in competitive equilibrium, and in competitive search equilibrium," Econometrica, 73(1), 175-202.

Rogerson, R., And R. Shimer (2011): "Search in Macroeconomic Models of the Labor Market," in Handbook of Labor Economics, vol. 4, chap. 7, pp. 619-700.

SHI, S. (2012): "Liquidity, Assets and Business Cycles," working paper, University of Toronto.

Shimer, R. (2005): "The Cyclical Behavior of Equilibrium Unemployment and Vacancies," American Economic Review, 95(1), 25-49.

Tobin, J. (1969): "A General Equilibrium Approach to Monetary Theory," Journal of Money, Credit and Banking, 1(1), 15-29.

Ungerer, C. (2012): "Monetary Policy , Hot Housing Markets And Household Debt," working paper, LSE.

Wallace, N. (1981): “A Modigliani-Miller Theorem for Open-Market Operations," American Economic Review, 71(3), 267-274.

Wasmer, E., And P. WeIL (2004): "The Macroeconomics of Labor and Credit Market Imperfections," American Economic Review, 94(4), 944-963.

Wheaton, W. C. (1990): "Vacancy, Search, and Prices in a Housing Market Matching Model," Journal of Political Economy, 98(6), 1270-1292.

Williamson, S. D. (2012): "Liquidity, Monetary Policy, and the Financial Crisis: A New Monetarist Approach," American Economic Review, 102(6), 2570-2605.

YANG, Z. (2013): "Search, Asset Liquidity and Business Cycles," working paper, Queen's University. 


\section{Appendices}

\section{A Data}

The measure of liquid assets $B_{t+1}$ consists of all liabilities of the federal government circulated inside the US economy. To obtain the measure, we use U.S. flow-of-funds data. In particular, we use Treasury securities (L.209 line 1), net of saving bonds (L.209 line 2, for financing World War II), net of holdings by the monetary authority (L.209 line 15 or L.108 line 12) and the rest of the world (L.209 line 12), plus reserves (L.108 line 32) and vault cash (L.108 line 33) of depositary institutions with the monetary authority, plus checkeable deposits and currency (L.108 line 34) net of the monetary authority's liabilities due to the rest of the world (L.108 line 39) and due to the federal government (L.108 line 35). This measure is similar to the one in Del Negro, Eggertsson, Ferrero, and Kiyotaki (2011), but is cleaned from liquid assets held by agents outside the US.

\section{B Individual Bargaining Values}

Recall that the amount of matched assets $m_{j}$ is predetermined for individual agents when they come to bargaining. They bargain on behalf the household and take into account the effects on the household's continuation value. Using individuals' type-specific budget constraints and noticing that a matched pair of individuals bargains over the margin $m_{j}$, one can write buyers and sellers' values of matches, $J^{v}$ and $J^{u}$, as

\section{Problem 2:}

Buyers' Value

$$
\begin{gathered}
J^{v}\left(m_{v}\right)=\int_{j \in u} u\left(c_{j}\right) d j+\int_{j \in v}\left[u\left(c_{j}\right)-\frac{\mu}{1+\nu} n_{j}^{1+\nu}\right] d j+\mathbb{E}_{\Gamma}\left[J\left(S^{\prime}, B^{\prime} ; \Gamma^{\prime}\right)\right] \text { s.t. } \\
c_{v}+\kappa_{v} v+\frac{b_{v}^{\prime}}{P}=w n_{v}+r s_{v}+q m_{v}+\frac{R b_{v}}{P} \\
s_{v}^{\prime}=(1-\delta) s_{v}-m_{v} \\
S^{\prime}=\int_{j \in v} s_{j}^{\prime} d j+\int_{j \in u} s_{j}^{\prime} d j, \quad B^{\prime}=\int_{j \in v} b_{j}^{\prime} d j+\int_{j \in u} b_{j}^{\prime} d j
\end{gathered}
$$

\section{Problem 3:}


Sellers' Value

$$
\begin{gathered}
J^{u}\left(m_{u}\right)=\int_{j \in u} u\left(c_{j}\right) d j+\int_{j \in v}\left[u\left(c_{j}\right)-\frac{\mu}{1+\nu} n_{j}^{1+\nu}\right] d j+\mathbb{E}_{\Gamma}\left[J\left(S^{\prime}, B^{\prime} ; \Gamma^{\prime}\right)\right] \text { s.t. } \\
c_{u}+\kappa_{u} u+\frac{b_{u}^{\prime}}{P}=r s_{u}+(1-\delta) s_{u}+\left(q-\frac{1}{\phi_{u}}\right) m_{u}+\frac{R b_{u}}{p} \\
s_{u}^{\prime}=\left(\frac{1}{\phi_{u}}-1\right) m_{u} \\
S^{\prime}=\int_{j \in v} s_{j}^{\prime} d j+\int_{j \in u} s_{j}^{\prime} d j, \quad B^{\prime}=\int_{j \in v} b_{j}^{\prime} d j+\int_{j \in u} b_{j}^{\prime} d j
\end{gathered}
$$

The marginal value of an additional match for a buyer (worker) is thus given by

$$
\begin{aligned}
-J_{m}^{v} & =-u^{\prime}\left(c_{v}\right) q+\beta \mathbb{E}_{\Gamma}\left[J_{S}\left(S^{\prime}, B^{\prime} ; \Gamma^{\prime}\right) \frac{\partial S^{\prime}}{\partial s_{v}^{\prime}} \frac{\partial s_{v}^{\prime}}{\partial\left(-m_{v}\right)}\right] \\
& =-u^{\prime}\left(c_{v}\right) q+\beta \mathbb{E}_{\Gamma}\left[J_{S}\left(S^{\prime}, B^{\prime} ; \Gamma^{\prime}\right)\right]
\end{aligned}
$$

and for a seller (entrepreneur) by

$$
\begin{aligned}
J_{m}^{u} & =u^{\prime}\left(c_{u}\right)\left(q-\frac{1}{\phi_{u}}\right)+\beta \mathbb{E}_{\Gamma}\left[J_{S}\left(S^{\prime}, B^{\prime} ; \Gamma^{\prime}\right) \frac{\partial S^{\prime}}{\partial s_{u}^{\prime}} \frac{\partial s_{u}^{\prime}}{\partial m_{u}}\right] \\
& =u^{\prime}\left(c_{u}\right)\left(q-\frac{1}{\phi_{u}}\right)+\beta \mathbb{E}_{\Gamma}\left[J_{S}\left(S^{\prime}, B^{\prime} ; \Gamma^{\prime}\right)\left(\frac{1}{\phi_{u}}-1\right)\right]
\end{aligned}
$$

\section{Proofs}

\section{C.1 Proposition 2}

We first simplify the first-order condition associated with the Nash bargaining solution to

$$
\frac{\omega}{\rho\left[q-\frac{1}{\phi_{u}}\right]+\frac{1-\phi_{u}}{\phi_{u}} q_{v}}=\frac{1-\omega}{q_{v}-q}
$$

by using $u^{\prime}\left(c_{v}\right) q_{v}=\beta \mathbb{E}_{\Gamma} J_{S}\left(S^{\prime}, B^{\prime} ; \Gamma^{\prime}\right)$ and $u^{\prime}\left(c_{u}\right)=\rho u^{\prime}\left(c_{v}\right)$. Then

$$
\omega \frac{\kappa_{v}}{\phi_{v}}=(1-\omega)\left[\rho\left(q-\frac{1}{\phi_{u}}\right)+\frac{1-\phi_{u} q_{u}}{\phi_{u}} \frac{\left(1-\phi_{u}\right) q_{v}}{1-\phi_{u} q_{u}}\right],
$$


which can be further simplified to

$$
\omega \frac{\kappa_{v}}{\phi_{v}}=(1-\omega) \rho\left(q-q_{u}\right)
$$

by realizing that $\rho \equiv \frac{q_{v}}{q_{r}}=\frac{\left(1-\phi_{u}\right) q_{v}}{1-\phi_{u} q_{u}}$. Solving the above equation for $\rho$ yields

$$
\rho=\frac{\omega}{1-\omega} \frac{\kappa_{v}}{\kappa_{u}} \frac{\phi_{u}}{\phi_{v}}=\gamma \theta
$$

which is the expression in (25). One can further express the asset price $q$ in terms of $\rho$ or $\phi_{u}$. Using the above expression along with the definition of $\rho$

$$
\rho \equiv \frac{q_{v}}{q_{r}}=\frac{\left(1-\phi_{u}\right) q_{v}}{1-\phi_{u} q_{u}}=\frac{\left(1-\phi_{u}\right)\left(q+\frac{\kappa_{v}}{\phi_{v}}\right)}{1-\phi_{u} q+\kappa_{u}},
$$

we can solve for the bargaining price $q$ as

$$
q=\frac{\rho\left(1+\kappa_{u}\right)-\left(1-\phi_{u}\right) \frac{\kappa_{v}}{\phi_{v}}}{1+(\rho-1) \phi_{u}}=\frac{\rho\left(1+\frac{\kappa_{u}}{\omega}\right)-\frac{\kappa_{v}}{\phi_{v}}}{1+(\rho-1) \phi_{u}}
$$

where the last line uses (25) again. Realizing that $\phi_{v}=\xi\left(\gamma^{-1} \rho\right)^{-\eta}$ and $\phi_{u}=\xi\left(\gamma^{-1} \rho\right)^{1-\eta}$ we can rewrite the asset price as a function of $\rho$

$$
q=\frac{\rho^{1-\eta}\left(1+\frac{\kappa_{u}}{\omega}\right)-\kappa_{v} \gamma^{-\eta} \xi^{-1}}{\rho^{-\eta}\left[1+(\rho-1) \xi\left(\gamma^{-1} \rho\right)^{1-\eta}\right]},
$$

or, equivalently, $\phi_{u}$

$$
\begin{aligned}
q & =\frac{\gamma^{1-\eta} \xi^{-1} \phi_{u}\left(1+\frac{\kappa_{u}}{\omega}\right)-\kappa_{v} \gamma^{-\eta} \xi^{-1}}{\gamma^{-\eta}\left(\xi^{-1} \phi_{u}\right)^{\frac{\eta}{\eta-1}}\left[1+\left(\gamma\left(\xi^{-1} \phi_{u}\right)^{\frac{1}{1-\eta}}-1\right) \phi_{u}\right]} \\
& =\frac{\gamma \phi_{u}\left(1+\frac{\kappa_{u}}{\omega}\right)-\kappa_{v}}{\xi^{\frac{1}{1-\eta}} \phi_{u}^{\frac{\eta}{\eta-1}}\left[1+\left(\gamma\left(\xi^{-1} \phi_{u}\right)^{\frac{1}{1-\eta}}-1\right) \phi_{u}\right]} .
\end{aligned}
$$

\section{C.2 Proposition 3}

By differentiating the bargaining price from (26) with respect to $\phi_{u}$, we get 


$$
\begin{aligned}
& \frac{\partial q}{\partial \phi_{u}}\left[\xi^{\frac{1}{1-\eta}} \phi_{u}^{\frac{\eta}{\eta-1}}\left[1+(\rho-1) \phi_{u}\right]\right] \\
& =\gamma\left(1+\frac{\kappa_{u}}{\omega}\right)-q \frac{\partial}{\partial \phi_{u}}\left[\xi^{\frac{1}{1-\eta}} \phi_{u}^{\frac{\eta}{\eta-1}}\left[1+\left(\gamma\left(\xi^{-1} \phi_{u}\right)^{\frac{1}{1-\eta}}-1\right) \phi_{u}\right]\right]
\end{aligned}
$$

where

$$
\frac{\partial}{\partial \phi_{u}}\left[\xi^{\frac{1}{1-\eta}} \phi_{u}^{\frac{\eta}{\eta-1}}\left[1+\left(\gamma\left(\xi^{-1} \phi_{u}\right)^{\frac{1}{1-\eta}}-1\right) \phi_{u}\right]\right]=\rho^{-1} \gamma\left[\phi_{u}\left(2 \rho-\frac{1-2 \eta}{1-\eta}\right)-\frac{\eta}{1-\eta}\right] .
$$

Note that $2 \rho-\frac{1-2 \eta}{1-\eta}=\frac{\eta}{1-\eta}+2 \rho-1$. A necessary and sufficient condition for $\frac{\partial q}{\partial \phi_{u}}>0$ is for the RHS of (34) to be non-negative. This is the case, whenever

$$
\phi_{u}<\left[\frac{\eta}{1-\eta}+\left(1+\frac{\kappa_{u}}{\omega}\right) \frac{\rho}{q}\right]\left[\frac{\eta}{1-\eta}+2 \rho-1\right]^{-1}
$$

This condition requires $\phi_{u}$ to be small enough for the asset price and asset liquidity to correlate positively. If, for instance, $\eta=0.5$ and $\rho>1$, then we would need $\phi_{u}<$ $\left[1+\left(1+\frac{\kappa_{u}}{\omega}\right) q^{-1} \rho\right](2 \rho)^{-1} \lesssim 0.5$

Note that $\frac{\partial q}{\partial \phi_{u}}>0$ implies $\frac{\partial q}{\partial \phi_{v}}<0$, because $\frac{\partial q}{\partial \phi_{v}}=\frac{\partial q}{\partial \phi_{u}} \frac{\partial \phi_{u}}{\partial \phi_{v}}$ and

$$
\frac{\partial \phi_{u}}{\partial \phi_{v}}=\frac{\eta-1}{\eta} \xi^{\frac{1}{\eta}} \phi_{v}^{-\frac{1}{\eta}}<0
$$

Hence, the same parameter restriction that ensures $\frac{\partial q}{\partial \phi_{u}}>0$ also ensures $\frac{\partial q}{\partial \phi_{v}}<0$.

\section{C.3 Corollary 1}

Suppose that $\kappa_{v} \rightarrow 0$ and $\kappa_{u} \rightarrow 0$. Then $q_{v} \rightarrow q$ and the excess value of an additional match for the buyers goes to

$$
-J_{m}^{v}=-u^{\prime}\left(c_{v}\right) q+\beta \mathbb{E}_{\Gamma}\left[J_{S}\left(S^{\prime}, B^{\prime} ; \Gamma^{\prime}\right)\right]=u^{\prime}\left(c_{v}\right)\left(q_{v}-q\right) \rightarrow 0
$$

Hence, buyers become indifferent between trading and not trading at the margin. For trading not to break down, the sellers must also have zero excess value. To see this, consider a negative excess value for sellers. They would then be better off not to engage in asset sales at the margin, such that trading would break down. Suppose, in contrast, that sellers' excess value is positive. Since in the absence of search costs buyers are indifferent between trading and not trading at any price, sellers can improve by demanding a price that maximizes their welfare from an additional match; i.e. sellers would choose a $q$ such that the excess value goes 
to zero, $J_{m}^{u} \rightarrow 0$, and they become indifferent with respect to an additional trade. Therefore,

$$
J_{m}^{u}=u^{\prime}\left(c_{u}\right)\left(q-\frac{1}{\phi_{u}}\right)+\frac{1-\phi_{u}}{\phi_{u}} \beta \mathbb{E}_{\Gamma}\left[J_{S}\left(S^{\prime}, B^{\prime} ; \Gamma^{\prime}\right)\right]=u^{\prime}\left(c_{v}\right)\left[\rho\left(q-\frac{1}{\phi_{u}}\right)+\frac{1-\phi_{u}}{\phi_{u}}\right] \rightarrow 0
$$

which shows that in the limit

$$
\rho\left(q-\frac{1}{\phi_{u}}\right)+\frac{1-\phi_{u}}{\phi_{u}}=0
$$

By rearranging we get

$$
\rho=\frac{1-\phi_{u}}{1-\phi_{u} q}
$$

Remember that when $\kappa_{v} \rightarrow 0$ and $\kappa_{v} \rightarrow 0$, the limit of $\rho \equiv \frac{q_{v}}{q_{r}}$ simplifies to

$$
\rho=\frac{\left(1-\phi_{u}\right) q}{1-\phi_{u} q}
$$

Equating conditions (35) and (36) then yields $q \rightarrow 1$, which implies $\rho \rightarrow 1$. Furthermore, we have that $\gamma \rightarrow \frac{\omega}{1-\omega}$, such that

$$
\theta=\frac{\rho}{\gamma} \rightarrow \frac{1-\omega}{\omega}, \quad \phi_{u} \rightarrow \xi\left(\frac{1-\omega}{\omega}\right)^{1-\eta}, \quad \phi_{v} \rightarrow \xi\left(\frac{1-\omega}{\omega}\right)^{-\eta}
$$

\section{Equilibrium Conditions and Steady State}

\section{D.1 Recursive Equilibrium Conditions}

We change the recursive equilibrium definition slightly by defining real liquidity $L=\frac{B}{P_{-1}}$ and adding aggregate output $Y$. Given the aggregate state variables $\Gamma=\left(K ; z_{a}, z_{\kappa}\right)$, we can solve the equilibrium system

$$
\left(K^{\prime}, L, C, I, N, Y, \phi_{u}, \rho, \rho_{u}, \rho_{v}, q_{v}, r, w, \pi\right)
$$

together with the exogenous laws of motion of $\left(z_{a}, z_{\kappa}\right)$, i.e., $z_{a}^{\prime}=\rho_{a} z_{a}+\epsilon_{a}^{\prime}$ and $z_{\kappa}^{\prime}=\rho_{\kappa} z_{\kappa}+\epsilon_{\kappa}^{\prime}$. To solve for these 14 endogenous variables, we use the following 14 equations:

1. The representative household's optimality conditions:

$$
\left(\frac{\rho_{v} C}{1-\chi}\right)^{-\sigma} w=\mu
$$




$$
\begin{gathered}
\rho_{v} \equiv \frac{1-\chi}{1-\chi+\rho^{-1 / \sigma} \chi}, \quad \rho_{u} \equiv \frac{\chi}{\rho^{1 / \sigma}(1-\chi)+\chi} \\
1=\beta \mathbb{E}_{\Gamma}\left[\left(\frac{\rho_{v}^{\prime} C^{\prime}}{\rho_{v} C}\right)^{-\sigma}\left[\chi \rho^{\prime}+1-\chi\right] \frac{1}{\pi^{\prime}}\right] \\
1=\beta \mathbb{E}_{\Gamma}\left[\left(\frac{\rho_{v}^{\prime} C^{\prime}}{\rho_{v} C}\right)^{-\sigma} \frac{\left(\chi \rho^{\prime}+1-\chi\right) r^{\prime}+(1-\delta)\left(\chi \rho^{\prime}+(1-\chi) q_{v}^{\prime}\right)}{q_{v}}\right] \\
I=\frac{\chi\left[\left(r+\left(\phi_{u} q_{v}-\left[\frac{(1-\omega) \rho}{\omega}+1\right] \kappa_{u}\right)(1-\delta)\right) K+\frac{L}{\pi}\right]-\rho_{u} C}{1-\phi_{u} q_{v}+\left[\frac{(1-\omega) \rho}{\omega}+1\right] \kappa_{u}}
\end{gathered}
$$

2. Final goods producers:

$$
r=e^{z_{a}} F_{K}(K, N), \quad w=e^{z_{a}} F_{N}(K, N), \quad Y=e^{z_{a}} F(K, N)
$$

3. Market clearing:

(a) Consumption goods

$$
\begin{aligned}
\left(\rho_{v}+\rho \rho_{u}\right) C+q_{v} K^{\prime}+L^{\prime}= & w N+\left[(\chi \rho+(1-\chi)) r+(1-\delta)\left(\chi \rho+(1-\chi) q_{v}\right)\right] K \\
& +[\chi \rho+(1-\chi)] \frac{L}{\pi}
\end{aligned}
$$

(b) Capital

$$
K^{\prime}=(1-\delta) K+I
$$

(c) Search market (note: $\gamma \equiv \frac{\omega}{1-\omega} \frac{\kappa_{v}}{\kappa_{u}}, \kappa_{u}=e^{z_{\kappa}} \bar{\kappa}_{u}, \kappa_{v}=e^{z_{\kappa}} \bar{\kappa}_{v}$ )

$$
q_{v}=\frac{\rho\left[1+\kappa_{u}+\rho \frac{(1-\omega) \kappa_{u}}{\omega}\right]}{1+(\rho-1) \phi_{u}}, \quad \phi_{u}=\xi\left(\gamma^{-1} \rho\right)^{1-\eta}
$$

(d) Liquid assets (note: $L^{\prime} \equiv \frac{B^{\prime}}{P}, \pi^{\prime} \equiv \frac{P^{\prime}}{P}$ )

$$
L^{\prime}=\frac{L}{\pi}
$$




\section{D.2 Steady State}

In deterministic steady state, any variable $X=X^{\prime}$. With a slight abuse of notation, we denote the steady state of $X$ as $X$ itself in this section. First notice that

$$
z_{a}=0, \quad z_{\kappa}=0
$$

such that $\kappa_{u}=\bar{\kappa}_{u}, \kappa_{v}=\bar{\kappa}_{v}$. We can now solve for all prices analytically. Market clearing for liquid assets implies

$$
\pi=1
$$

Next, we use (37) to obtain

$$
\rho=\chi^{-1}\left[\beta^{-1}-(1-\chi)\right], \quad \rho_{v} \equiv \frac{1-\chi}{1-\chi+\rho^{-1 / \sigma} \chi}, \quad \rho_{u} \equiv \frac{\chi}{\rho^{1 / \sigma}(1-\chi)+\chi}
$$

This directly implies

$$
\phi_{u}=\xi\left(\gamma^{-1} \rho\right)^{1-\eta}, \quad q_{v}=\frac{\rho\left[1+\kappa_{u}+\rho \frac{(1-\omega) \kappa_{u}}{\omega}\right]}{1+(\rho-1) \phi_{u}}
$$

From (38) and (40) we have

$$
r=\frac{\frac{q_{v}}{\beta}-(1-\delta)\left(\chi \rho+(1-\chi) q_{v}\right)}{\chi \rho+1-\chi}, \quad w=(1-\alpha)\left(\frac{r}{\alpha}\right)^{\frac{\alpha}{\alpha-1}}, \quad C=\left(\frac{w}{\mu}\right)^{1 / \sigma} \frac{1-\chi}{\rho_{v}}
$$

Now, we express labor supply $N$ as a function of $K$

$$
N=\left(\frac{r}{\alpha}\right)^{\frac{1}{1-\alpha}} K
$$

Notice that investment $I=\delta K$ and real liquidity can be rewritten as a function of $K$ using $(39)$

$$
L=\chi^{-1}\left\{\rho_{u} C+\left[\delta-\chi r-\phi_{u} q_{u}(\delta+\chi(1-\delta))\right] K\right\} .
$$

Since $N$ and $L$ are both linear in $K$, we solve $K$ from the household's budget constraint

$$
K=\frac{\left(\rho_{v}+\rho_{u}\right) C}{\frac{(1-\alpha)}{\alpha} r+A_{K}+(\rho-1)\left[\delta-\chi r-\phi_{u} q[\delta+\chi(1-\delta)]\right]}
$$

where $A_{K}=(\chi \rho+1-\chi) r+(1-\delta)\left(\chi \rho+(1-\chi) q_{v}\right)-q_{v}$. 


\section{E The Social Planner's Problem}

\section{E.1 Implementability Condition and the Planner's Problem}

To derive the implementability condition, the key is to substitute out prices and quantities of financial assets from the representative household's budget constraint using the optimality conditions associated with the individual portfolio choice and labor supply decisions.

Implementability condition. First, we simplify some notation, such that the budget constraint (30) becomes

$$
A_{c, t} C_{t}+q_{v, t} K_{t+1}+L_{t+1}=w_{t} N_{t}+A_{K, t} K_{t}+R_{L, t} L_{t}
$$

where we collect terms as

$$
\begin{gathered}
A_{c, t} \equiv \rho_{v, t}+\rho_{u, t} \rho_{t}, \quad A_{K, t} \equiv\left[\chi \rho_{t}+(1-\chi)\right] r_{t}+\left[\chi \rho_{t}+(1-\chi) q_{v, t}\right](1-\delta) \\
L_{t} \equiv \frac{B_{t}}{P_{t-1}}, \quad R_{L, t} \equiv \frac{\chi \rho_{t}+(1-\chi)}{\pi_{t}}
\end{gathered}
$$

Notice that $L_{t}$ is the real value of liquidity and $R_{L, t}$ is the rate of return to holding liquid assets.

Second, multiplying both sides by $\beta^{t} u\left(c_{v, t}\right)$ and taking expectations at $t=0$, we get

$$
\mathbb{E}_{0} \beta^{t} u^{\prime}\left(c_{v, t}\right)\left[A_{c, t} C_{t}+q_{v, t} K_{t+1}+L_{t+1}\right]=\mathbb{E}_{0} \beta^{t} u^{\prime}\left(c_{v, t}\right)\left[w_{t} N_{t}+A_{K, t} K_{t}+R_{L, t} L_{t}\right]
$$

Using the first order condition for capital and bonds, (23) and (24),

$$
\beta^{t} u^{\prime}\left(c_{v, t}\right) q_{v, t}=\mathbb{E}_{t} \beta^{t+1} u^{\prime}\left(c_{v, t+1}\right) A_{K, t+1}, \quad \beta^{t} u^{\prime}\left(c_{v, t}\right)=\mathbb{E}_{t} \beta^{t+1} u^{\prime}\left(c_{v, t+1}\right) R_{L, t+1}
$$

and rearranging further yields

$$
\begin{aligned}
& \mathbb{E}_{0}\left\{\beta^{t} u^{\prime}\left(c_{v, t}\right)\left(A_{c, t} C_{t}-w_{t} N_{t}\right)+\left[\mathbb{E}_{t}\left[\beta^{t+1} u^{\prime}\left(c_{v, t+1}\right) A_{K, t+1}\right]\right] K_{t+1}+\left[\mathbb{E}_{t}\left[\beta^{t+1} u^{\prime}\left(c_{v, t+1}\right) R_{L, t+1}\right]\right] L_{t+1}\right\} \\
= & \mathbb{E}_{0} \beta^{t} u^{\prime}\left(c_{v, t}\right)\left(A_{K, t} K_{t}+R_{L, t} L_{t}\right),
\end{aligned}
$$

which can be simplified by using the Law of Iterated Expectations and by substituting out wage rate $w_{t}$ (from the first order condition for labor supply, i.e., (20)) to obtain a reformulated flow-of-funds constraint

$$
\begin{aligned}
& \mathbb{E}_{0} \beta^{t}\left[u^{\prime}\left(c_{v, t}\right) A_{c, t} C_{t}-\mu N_{t}\right]+\mathbb{E}_{0}\left[\beta^{t+1} u^{\prime}\left(c_{v, t+1}\right)\left(A_{K, t+1} K_{t+1}+R_{L, t+1} L_{t+1}\right)\right] \\
= & \mathbb{E}_{0} \beta^{t} u^{\prime}\left(c_{v, t}\right)\left(A_{K, t} K_{t}+R_{L, t} L_{t}\right) .
\end{aligned}
$$


Finally, summing the above constraint over all periods $t=0,1,2, \ldots, \mathrm{T}$, letting $T \rightarrow \infty$, and applying the transversality conditions for financial assets, ${ }^{32}$ we retrieve the following implementability condition:

$$
\mathbb{E}_{0} \sum_{t=0}^{\infty} \beta^{t}\left[u^{\prime}\left(\frac{\rho_{v, t} C_{t}}{1-\chi}\right) A_{c, t} C_{t}-\mu N_{t}\right]=u^{\prime}\left(\frac{\rho_{v, 0} C_{0}}{1-\chi}\right)\left[A_{K, 0} K_{0}+R_{L, 0} L_{0}\right]
$$

This condition depends on the allocations of consumption $C_{t}$, labor supply $N_{t}$ and search intensity $\theta_{t}$ (because $\rho_{v, t}, A_{c, t}, A_{K, 0}, R_{L, 0}$ are functions of $\rho_{t}=\gamma \theta_{t}$ ). However, the condition is independent of capital stock $K_{t}$ and liquid assets $L_{t}$, except for the initial stocks $K_{0}$ and $L_{0}$. Households' portfolio choices and endogenous asset prices have thus been substituted out.

The social planner's problem. The social planner maximizes social welfare (1), subject to the implementability condition (42) and the aggregate resource constraint (33). In order to avoid determining the initial price level of nominal assets and inflation in period 0, we assume that $B_{0}=0$ and $L_{0}=0$ and money is introduced at the end of time 0 . Let $\Phi$ be the Lagrangian multiplier associated with the implementability condition and let

$$
\begin{aligned}
W\left(C_{t}, N_{t}, \rho_{t} ; \Phi\right)= & \chi u\left(\frac{\rho_{u, t} C_{t}}{\chi}\right)+(1-\chi)\left[u\left(\frac{\rho_{v, t} C_{t}}{1-\chi}\right)-\mu \frac{N_{t}}{1-\chi}\right] \\
& +\Phi\left[u^{\prime}\left(\frac{\rho_{v, t} C_{t}}{1-\chi}\right) A_{c, t} C_{t}-\mu N_{t}\right]
\end{aligned}
$$

\section{Problem 4:}

Given $K_{0}$, the social planner solves

$$
\max _{\left\{C_{t}, N_{t}, \rho_{t}, K_{t+1}\right\}_{t=0}^{\infty}} \mathbb{E}_{0} \sum_{t=0}^{\infty} \beta^{t} W\left(C_{t}, N_{t}, \rho_{t}, \Phi\right)-\Phi u^{\prime}\left(\frac{\rho_{v, 0} C_{0}}{1-\chi}\right) A_{K, 0} K_{0}
$$

s.t. $\quad C_{t}+\left(1+\gamma_{v} \rho_{t}+\kappa_{u}\right) K_{t+1}=e^{z_{t}} F\left(K_{t}, N_{t}\right)+\left[1+\gamma_{v} \rho_{t}+\kappa_{u}\right](1-\delta) K_{t}, \quad \forall t \geq 0$.

The first-order conditions for this problem imply that for $t \geq 0$ optimal capital choices satisfy

$$
W_{C, t}\left(1+\kappa_{v} \rho_{t}+\kappa_{u}\right)=\beta \mathbb{E}_{t}\left[W_{C, t+1} e^{z_{t+1}} F_{K}\left(K_{t+1}, N_{t+1}\right)+\left(1+\kappa_{v} \rho_{t+1}+\kappa_{u}\right)(1-\delta)\right]
$$

${ }^{32}$ The transversality conditions (for capital and liquid assets) are the no-arbitrage conditions

$$
\lim _{T \rightarrow \infty} \mathbb{E}_{0} \beta^{T+1} u^{\prime}\left(c_{v, T+1}\right) A_{K, T+1} K_{T+1}=0, \quad \lim _{T \rightarrow \infty} \mathbb{E}_{0} \beta^{T+1} u^{\prime}\left(c_{v, T+1}\right) R_{L, T+1} L_{T+1}=0
$$


and for $t \geq 1$ optimal consumption, labor, and search intensity choices satisfy

$$
\begin{gathered}
W_{N, t}=-W_{C, t} e^{z_{t}} F_{N}\left(K_{t}, N_{t}\right), \\
W_{\rho, t}=W_{C, t} \gamma_{v}\left[K_{t+1}-(1-\delta) K_{t}\right] .
\end{gathered}
$$

The partial derivatives of $W\left(C_{t}, N_{t}, \rho_{t} ; \Phi\right)$ are derived in the next section. The optimal consumption, labor, and search intensity at $t=0$ have additional terms due to the presence of the initial asset position.

\section{E.2 Optimality Conditions}

Recall that

$W\left(C_{t}, N_{t}, \rho_{t} ; \Phi\right)=\chi u\left(\frac{\rho_{u, t} C_{t}}{\chi}\right)+(1-\chi)\left[u\left(\frac{\rho_{v, t} C_{t}}{1-\chi}\right)-\mu \frac{N_{t}}{1-\chi}\right]+\Phi\left[u^{\prime}\left(\frac{\rho_{v, t} C_{t}}{1-\chi}\right) A_{c, t} C_{t}-\mu N_{t}\right]$

where

$$
\begin{aligned}
\frac{\rho_{u, t} C_{t}}{\chi} & =\frac{1}{\rho_{t}^{1 / \sigma}(1-\chi)+\chi} C_{t}, \\
\frac{\rho_{v, t} C_{t}}{1-\chi} & =\frac{\rho_{t}^{1 / \sigma}}{(1-\chi)+\chi \rho_{t}^{1 / \sigma}} C_{t}=\frac{1}{(1-\chi) \rho_{t}^{-1 / \sigma}+\chi} C_{t}, \\
A_{c, t} & =\rho_{v, t}+\rho_{u, t} \rho_{t}=\frac{1-\chi}{(1-\chi) \rho_{t}^{-1 / \sigma}+\chi}+\frac{\chi \rho_{t}}{\rho_{t}^{1 / \sigma}(1-\chi)+\chi} .
\end{aligned}
$$

Note that

$$
\begin{aligned}
\frac{\partial u\left(\frac{\rho_{u, t} C_{t}}{\chi}\right)}{\partial \rho_{t}} & =-\frac{(1-\chi) \rho_{t}^{1 / \sigma} \ln \rho_{t}}{\left[\rho_{t}^{1 / \sigma}(1-\chi)+\chi\right]^{2}} \frac{C_{t}}{\chi} u^{\prime}\left(\frac{\rho_{u, t} C_{t}}{\chi}\right) \equiv \rho_{u u, t} \frac{C_{t}}{\chi} u^{\prime}\left(\frac{\rho_{u, t} C_{t}}{\chi}\right), \\
\frac{\partial u\left(\frac{\rho_{v, t} C_{t}}{1-\chi}\right)}{\partial \rho_{t}} & =-\frac{(1-\chi) \rho_{t}^{-1 / \sigma} \ln \rho_{t}}{\left[\rho_{t}^{-1 / \sigma}(1-\chi)+\chi\right]^{2}} \frac{C_{t}}{1-\chi} u^{\prime}\left(\frac{\rho_{v, t} C_{t}}{1-\chi}\right) \equiv \rho_{v v, t} \frac{C_{t}}{1-\chi} u^{\prime}\left(\frac{\rho_{v, t} C_{t}}{1-\chi}\right), \\
\frac{\partial A_{c, t}}{\partial \rho_{t}} & =-\frac{(1-\chi)^{2} \rho_{t}^{-1 / \sigma} \ln \rho_{t}}{\left[\rho_{t}^{-1 / \sigma}(1-\chi)+\chi\right]^{2}}+\chi \frac{\left[\rho_{t}^{1 / \sigma}(1-\chi)+\chi\right]-(1-\chi) \rho_{t}^{1+1 / \sigma} \ln \rho_{t}}{\left[\rho_{t}^{1 / \sigma}(1-\chi)+\chi\right]^{2}} \equiv \rho_{A, t} .
\end{aligned}
$$


We then obtain the partial derivatives of $W$ for $t \geq 1$ as

$$
\begin{aligned}
W_{N, t} & =-(1+\Phi) \mu \\
W_{C, t} & =\rho_{u, t} u^{\prime}\left(\frac{\rho_{u, t} C_{t}}{\chi}\right)+\left(\rho_{v, t}+\Phi A_{c, t}\right) u^{\prime}\left(\frac{\rho_{v, t} C_{t}}{1-\chi}\right)+\frac{\Phi \rho_{v, t} A_{c, t}}{1-\chi} u^{\prime \prime}\left(\frac{\rho_{v, t} C_{t}}{1-\chi}\right) C_{t} \\
W_{\rho, t} & =\left[\rho_{u u, t} u^{\prime}\left(\frac{\rho_{u, t} C_{t}}{\chi}\right)+\rho_{v v, t} u^{\prime}\left(\frac{\rho_{v, t} C_{t}}{1-\chi}\right)\right] C_{t}+\Phi\left[\rho_{v v, t} \frac{C_{t}}{1-\chi} u^{\prime \prime}\left(\frac{\rho_{v} C_{t}}{1-\chi}\right) A_{c, t}+u^{\prime}\left(\frac{\rho_{v, t} C_{t}}{1-\chi}\right) \rho_{A, t}\right] C_{t} \\
& =\left[\rho_{u u, t} u^{\prime}\left(\frac{\rho_{u, t} C_{t}}{\chi}\right)+\left(\rho_{v v, t}+\Phi \rho_{A, t}\right) u^{\prime}\left(\frac{\rho_{v, t} C_{t}}{1-\chi}\right)\right] C_{t}+\frac{\Phi \rho_{v v, t} A_{c, t}}{1-\chi} u^{\prime \prime}\left(\frac{\rho_{v, t} C_{t}}{1-\chi}\right) C_{t}^{2} .
\end{aligned}
$$

Finally for $t=0$, the first-order conditions for labor and search intensity read

$$
W_{N, 0}=\left[-W_{C, 0}+\frac{\Phi \rho_{v, 0}}{1-\chi} u^{\prime \prime}\left(\frac{\rho_{v, 0} C_{0}}{1-\chi}\right) A_{K, 0} K_{0}\right] e^{z_{0}} F_{N}\left(K_{0}, N_{0}\right)
$$

$W_{\rho, 0}=W_{C, 0} \gamma_{v}\left[K_{1}-(1-\delta) K_{0}\right]+\Phi K_{0}\left[\frac{C_{0}}{1-\chi} u^{\prime \prime}\left(\frac{\rho_{v, 0} C_{0}}{1-\chi}\right) \frac{\partial \rho_{v, 0}}{\partial \rho_{0}} A_{K, 0}+u^{\prime}\left(\frac{\rho_{v, 0} C_{0}}{1-\chi}\right) \frac{\partial A_{K, 0}}{\partial \rho_{0}}\right]$,

where

$$
\frac{\partial \rho_{v, 0}}{\partial \rho_{0}}=-\frac{(1-\chi) \rho_{0}^{-1 / \sigma} \ln \rho_{0}}{\left[\rho_{0}^{-1 / \sigma}(1-\chi)+\chi\right]^{2}}, \quad \frac{\partial A_{K, 0}}{\partial \rho_{0}}=\chi e^{z_{0}} F_{N}\left(K_{0}, N_{0}\right)+(1-\delta)(1-\chi) \frac{\partial q_{v, 0}}{\partial \rho_{0}}
$$

We are left to give an expression for $\frac{\partial q_{v, 0}}{\partial \rho_{0}}$. Noticing that $q_{v}=\frac{\rho\left[1+\kappa_{u}+\rho \frac{(1-\omega) \kappa_{u}}{\omega}\right]}{1+(\rho-1) \phi_{u}}$ and $\phi_{u}=$ $\xi\left(\gamma^{-1} \rho\right)^{1-\eta}$, we can express

$$
\begin{aligned}
\frac{\partial q_{v, 0}}{\partial \rho_{0}}= & \frac{\left[1+\kappa_{u}+\frac{2(1-\omega) \kappa_{u} \rho_{0}}{\omega}\right]\left[1+\xi \gamma^{\eta-1} \rho_{0}^{1-\eta}\left(\rho_{0}-1\right)\right]}{\left[1+\xi \gamma^{\eta-1}\left(\rho_{0}-1\right) \rho_{0}^{1-\eta}\right]^{2}} \\
& -\frac{\xi \gamma^{\eta-1} \rho_{0}^{1-\eta}\left[1+\kappa_{u}+\frac{(1-\omega) \kappa_{u} \rho_{0}}{\omega}\right]\left[\rho_{0}+(1-\eta)\left(\rho_{0}-1\right)\right]}{\left[1+\xi \gamma^{\eta-1}\left(\rho_{0}-1\right) \rho_{0}^{1-\eta}\right]^{2}}
\end{aligned}
$$

\section{E.3 Optimal Search Intensity}

To characterize the full planner solution we would need to resort to numerical simulations. In order to derive some analytical results, we focus on the steady state instead. We can compute the planner's choice of $\rho$ from the steady state versions of equations (43) and (23):

$$
\begin{gathered}
1+\gamma_{v} \rho+\kappa_{u}=\beta\left[F_{K}(K, N)+\left(1+\gamma_{v} \rho+\kappa_{u}\right)(1-\delta)\right] \\
q_{v}=\beta\left[(\chi \rho+1-\chi) F_{K}(K, N)+\left[\chi \rho+(1-\chi) q_{v}\right](1-\delta)\right]
\end{gathered}
$$


Figure 4: The constraint efficient level of $\rho$

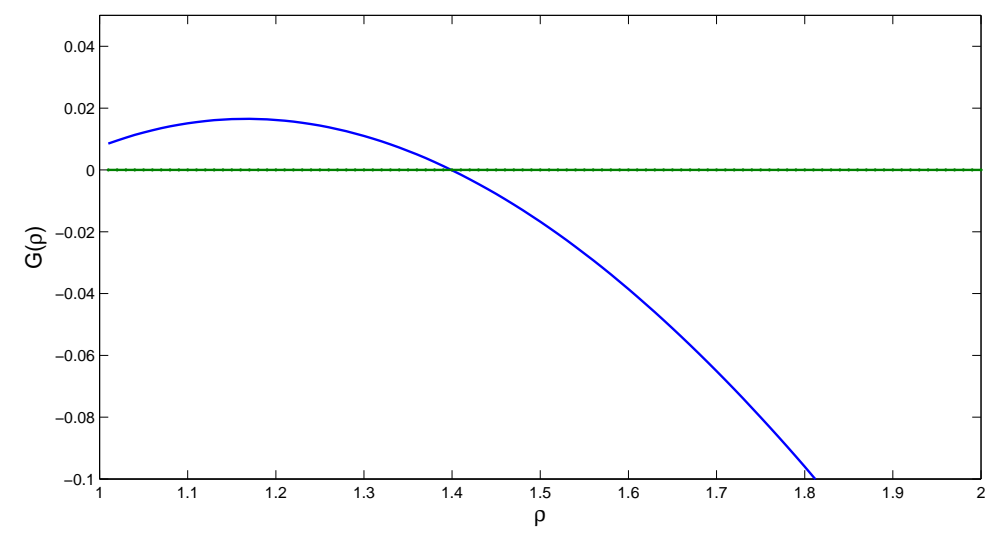

where the second equation is the household's steady state optimality condition with respect to equity claims. Subsituting out $F_{K}(K, N)$ reduces the above to

$$
[1-\beta(1-\delta)(1-\chi)] q_{v}-\beta \chi(1-\delta) \rho=[1-\beta(1-\delta)]\left[1+\gamma_{v} \rho+\kappa_{u}\right][\chi \rho+1-\chi]
$$

Using the bargaining solution to substitute out $q_{v}$ in the above equation, we derive a function $G(\rho)=0$ that pins down $\rho$ in terms of parameters (see Figure 4). ${ }^{33}$ The solution $G\left(\rho^{S P}\right)=0$ yields the constrained efficient level of $\rho$, which is related to the optimal level of search market tightness. Given our calibration, we have $\rho^{S P}=1.39$.

In the competitive economy, the steady state value of $\rho$ equals

$$
\rho^{C E}=\chi^{-1}\left(\frac{\pi}{\beta}-(1-\chi)\right)
$$

which, in our calibration is about $\rho^{C E}=1.18$. Since $\rho^{S P}>\rho^{C E}$, the social planner prefers a lower level of steady-state risk-sharing compared to the decentralized economy. This is equivalent to a deeper search market from the seller perspective (higher search market tightness $\theta$ ). Intuitively, entrepreneurs benefit from strong demand, as this increases the sales rate and relaxes their financing constraints. The social planner endogenizes this positive externality of stronger buyer participation and, thus, picks a higher value of $\rho$. Interestingly, the

${ }^{33}$ This function reads

$$
\begin{aligned}
G(\rho)= & {\left[\frac{\rho^{1-\eta}\left(1+\frac{\kappa_{u}}{\omega}\right)-\kappa_{v} \gamma^{-\eta} \xi^{-1}}{\rho^{-\eta}\left[1+(\rho-1) \xi\left(\gamma^{-1} \rho\right)^{1-\eta}\right]}+\frac{\kappa_{v}}{\xi}\left(\gamma^{-1} \rho\right)^{\eta}\right]-\frac{\beta \chi(1-\delta) \rho}{1-\beta(1-\delta)(1-\chi)} } \\
& -\frac{1-\beta(1-\delta)}{1-\beta(1-\delta)(1-\chi)}\left[1+\gamma_{v} \rho+\kappa_{u}\right][\chi \rho+1-\chi]
\end{aligned}
$$


constrained efficient risk-sharing level does not fall between the first-best value, $\rho=1$, and that of the decentralized economy, which illustrates the non-linearities in the search market set-up. The divergence between the competitive and the constrained efficient economy are likely to carry over to the dynamic behavior, i.e. the social planner would not let $\rho$ drop as severely as in the numerical examples in Section 4 to prevent financial constraints from tightening too much.

Notice that, for a given set of parameters $\left\{\chi, \beta, \delta, \kappa_{u}, \kappa_{v}, \gamma, \xi\right\}$, there may exist a value of the supply elasticity of matches $\eta=\eta^{S P}$, such that $\rho^{S P}=\rho^{C E}$. In this case, the competitive economy would be constrained efficient in the steady state. This is the (implicit) "Hosios condition" of our asset search framework. However, the supply elasticity varies with the underlying institutional design of the search market and may, hence, deviate from $\eta^{S P}$. 